تحليل ريسك سيلاب شهرى بندرعباس با استفاده از مدلهاى يادگيرى ماشين و تحليل

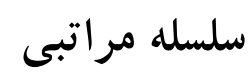

$$
\begin{aligned}
& \text { يو سف احمدى: دانشجوى دكترى علوم و مهندسى آبخيزدارى، برديس قشم، دانشكاه هرمزكان }
\end{aligned}
$$

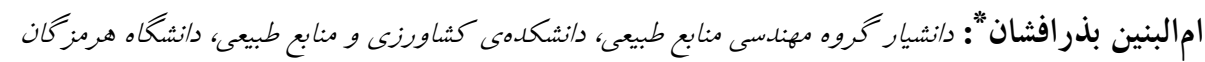

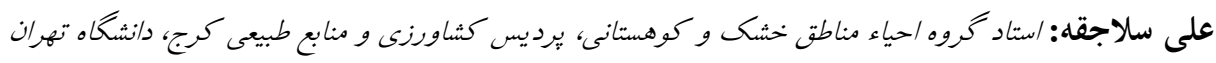

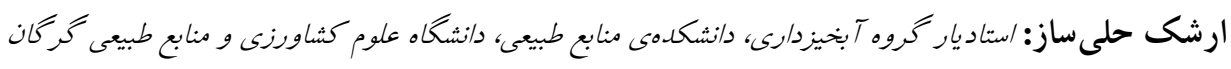

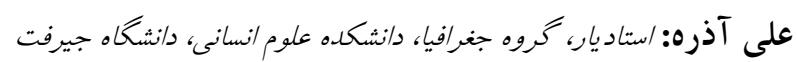

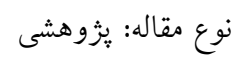

تاريخجه مقاله (تاريخ دريافت:

جكيده

توسعلى مناطق شهرى و روستايى، تبديل اراضى و بهرهبردارى بيش از ظرفيت منـابع طبيعى در دهـهـاى

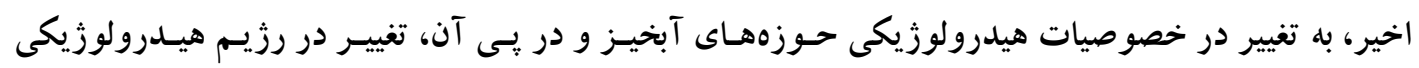

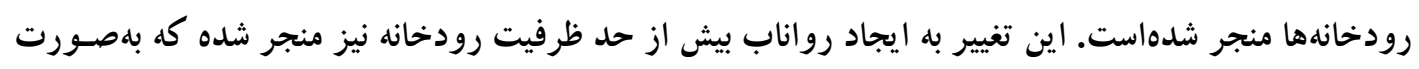
سيلابهاى مخرب ديده مىشو د. در اين مطالعه، تحليل ريسك سيلاب شهرى بندرعباس با استفاده از دو مـدل

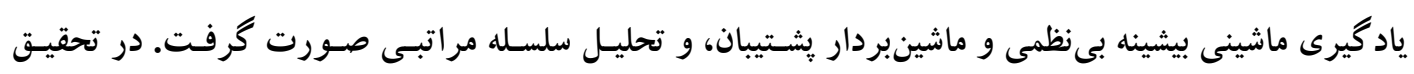

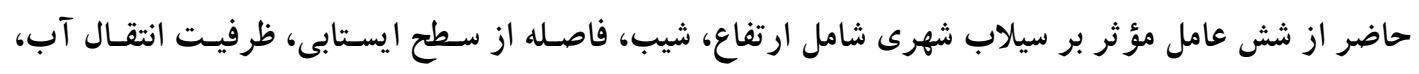

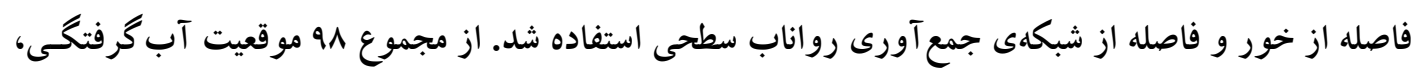

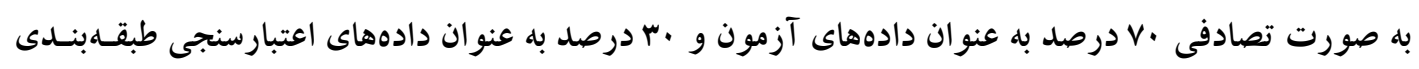

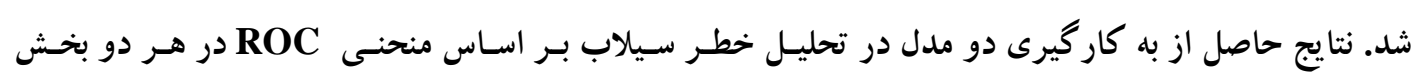

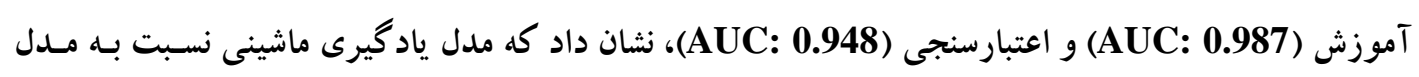

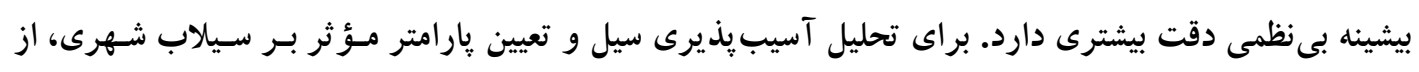

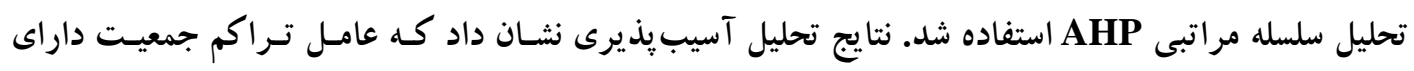

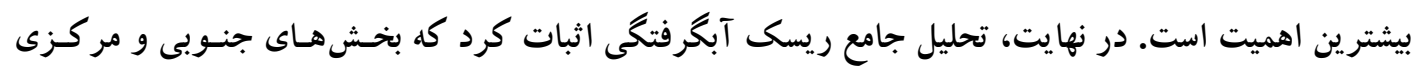

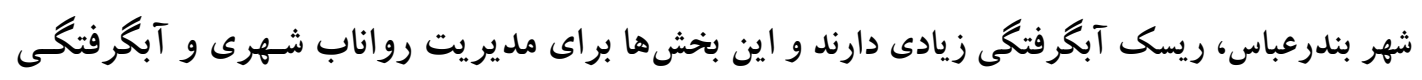
در اولويت بالايى هستند. تو سعهى فضاى سبز و افزايش ظرفيت سيستم جمع آورى رواناب خيابانها، از جمله اقدامات مهم براى كاهش ريسك آب گرفتكى شهرى است. همجنسين توزيـع مكـانى تـراكم جمعيتسى و تـراكم شهرى در بندرعباس، نامتوازن بود و اين موضوع بايد در برنامههاى مديريتى ايسن شهر لحساظ شـود تـا ميـزان تمركز جمعيتى در مناطق داراى ريسك زياد كاهش يابد.

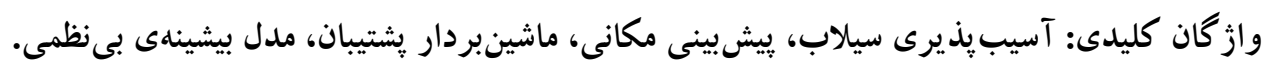


1ـ مقدمه

سيل يكى از رويدادهاى طبيعى است كه هر ساله به تلفات انسانى و خسارت به سـاختمانهـا، تأسيسـات، بـاغهـا،

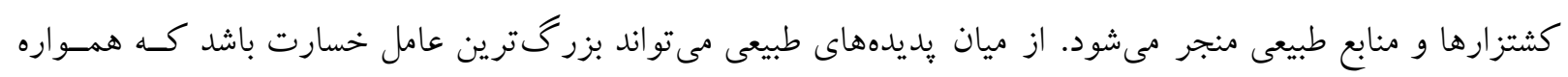

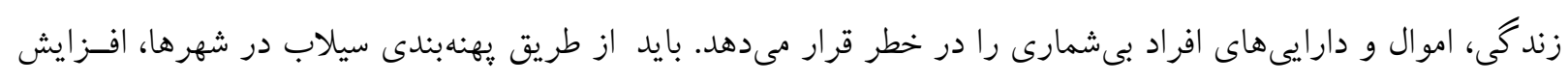

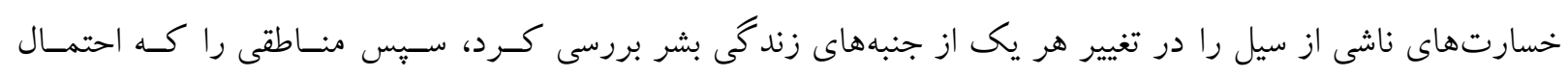

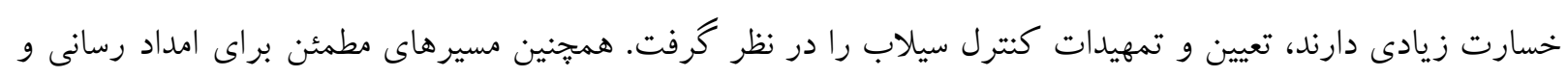
مكانهاى امن براى اسكان مردم را شناسايى كرد (Paul et al., 2019).

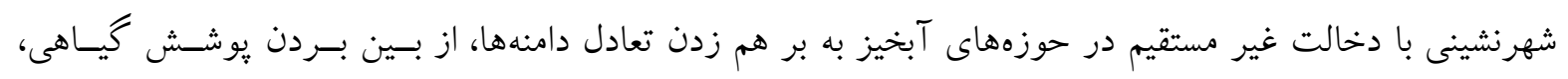

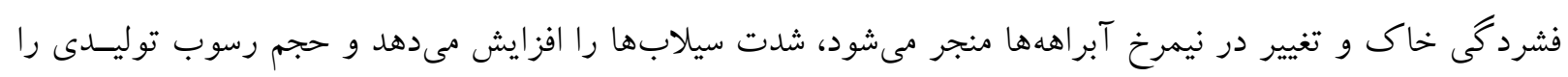

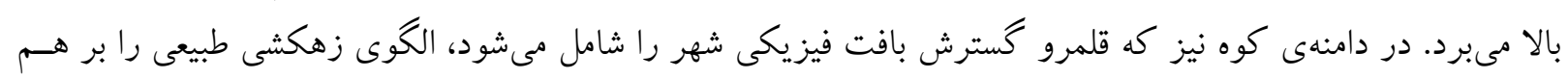
مىزند و خطر سيلابهاى شهرى را بيشتر مى كند (Hosseinzadeh, 2004). سيل گرفتكى شهرها و و خسارات و زيانهاى

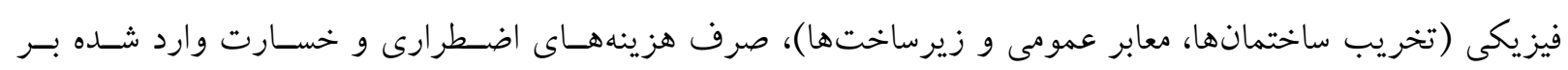

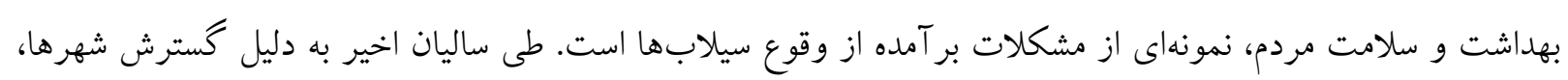

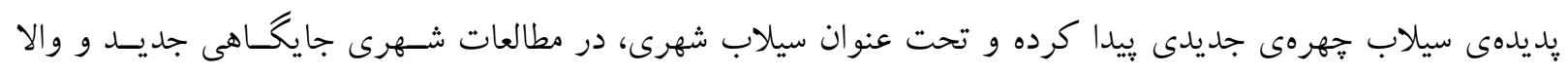
يافتهاست (Ghahroodi Taloodi, 2009). وسعت حوضههاى آبخيز مشرف به شهر بندرعباس، سطح قابل توجهى را بـهـ

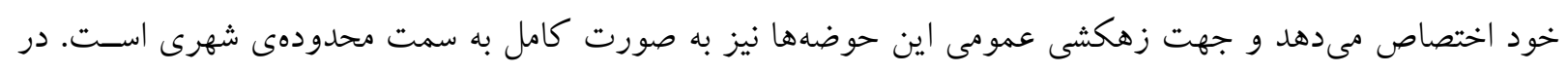
اين راستا، سيستم اطلاعات جغرافيايى (GIS') به همراه مدلها ابزارهايى كليدى است كه با داشتن مدلسازى و و برخسى آناليزها، در كنترل سيلابها مؤثر است (Roostayi, 2008).

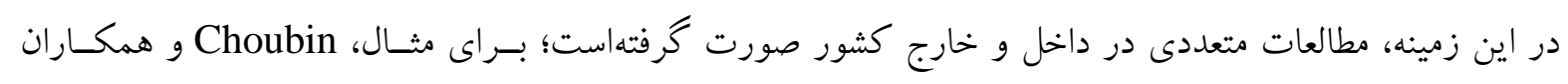

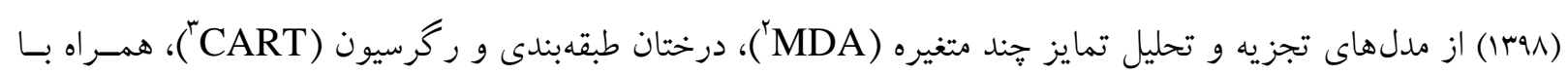

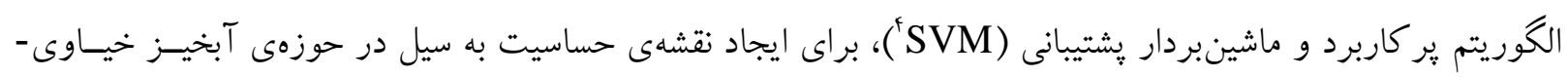

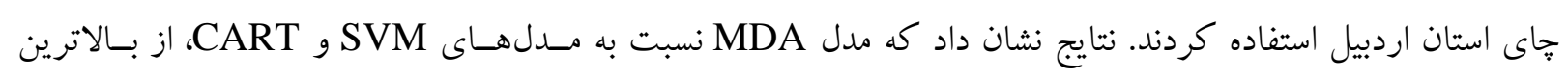
دقت يُش بينى برخوردار است. Ghalesari و همكاران نيز در سال و9ها يزوهشى را با استفاده از مدل بردار ڤشتيبان و

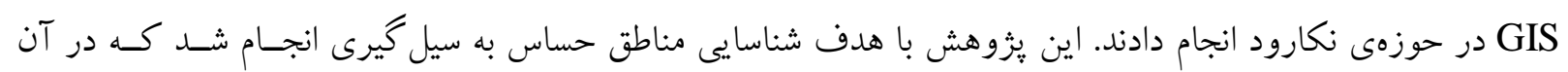

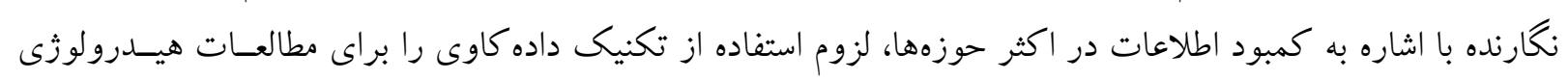
توجيه مى كرد. نامبرده با بهره كيرى از GIS و GIS

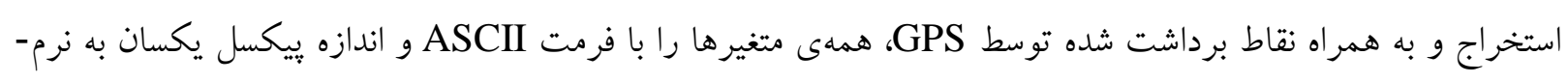

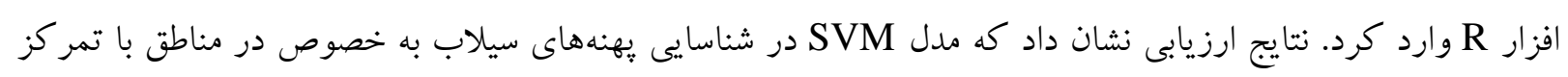

\footnotetext{
${ }^{1}$ Geography Inforamtion System

${ }^{2}$ Multivariate Diference Analysis

${ }^{3}$ Classification and Regression Tree (CART) models

${ }_{5}^{4}$ Support Vector Machine

${ }^{5}$ Environment for Visualizing Images
} 
سكونت كاه انسانى، دقت بيشترى دارد و در آن مناطق، حساسيت به سيل گيرى بيشتر است. در همين سال Vafakhah

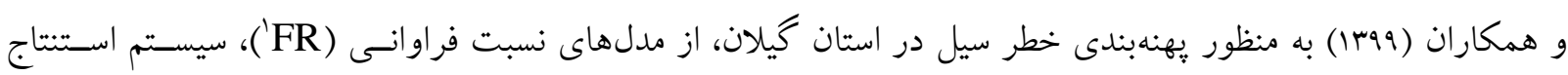
عصبى فازى تطبيقى (ANFIS) و مدلهاى جنكل تصادفى (RF) استفاده كردند. نتايج اعتبارسنجى مدلها نشان داد كـــ

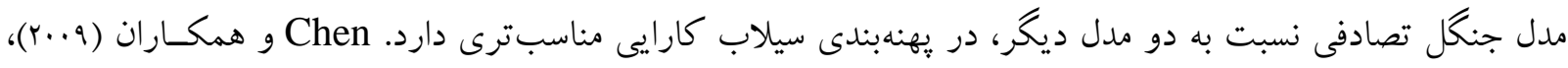

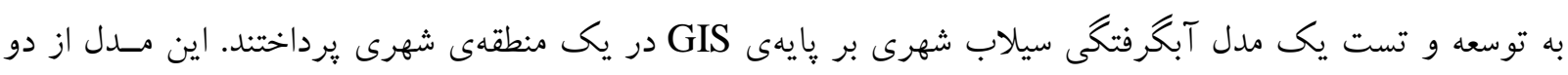

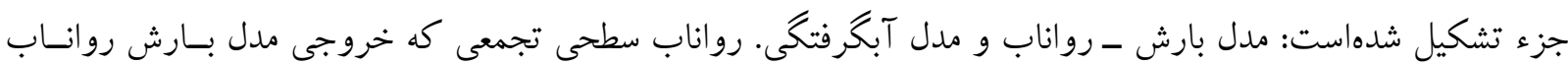

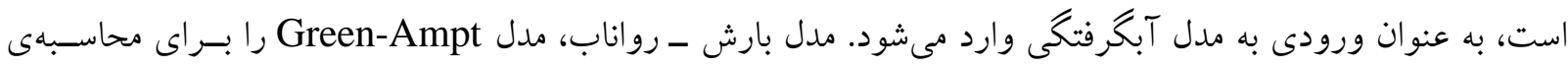

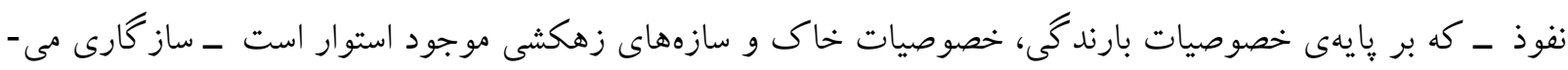

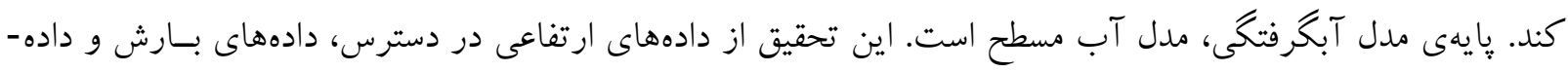
هاى جمع آورى شدهى سيلابهاى قبلى به منظور توسعه، اجرا و ارزيابى رويكرد مدل استفاده كـردهاسـت. Sahana و

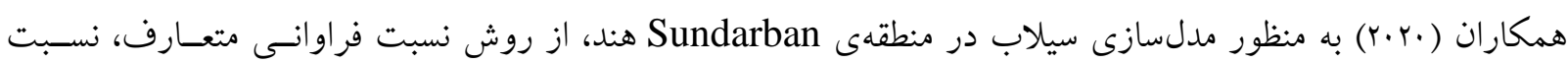
فروانى اصلاح شده و ماشين بردار يشتيبان استفاده كردند. نتايج آنان نشان داد كه مدل ماشينبردار يشتيبان نسبت به دو

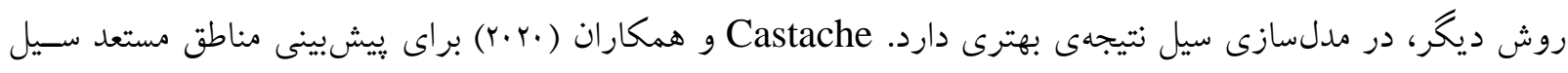

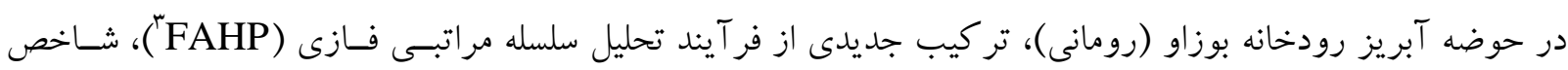

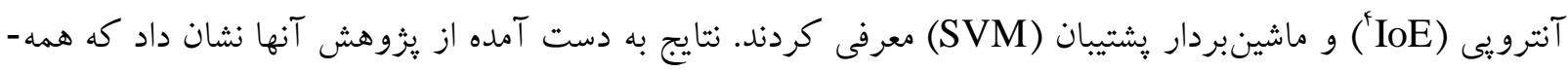

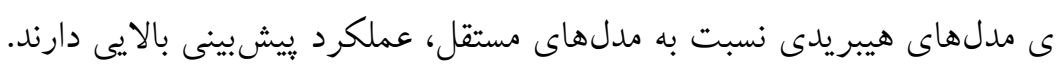

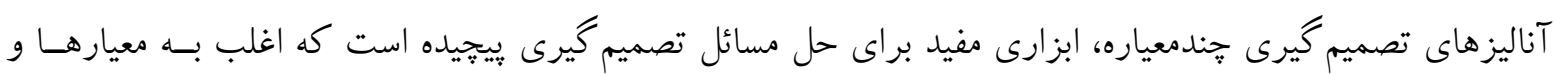
دادههاى غيرقابل مقايسه نياز دارد (Hwang and Yoon, 1981). محققان از تركيب اين روشها با با GIS به طـور قابـل توجهى به ويزه در خصوص سيل استفاده كردهاند (Jaffari et al, 2014 \& Paquette and Lowry Fernandez, 2012.

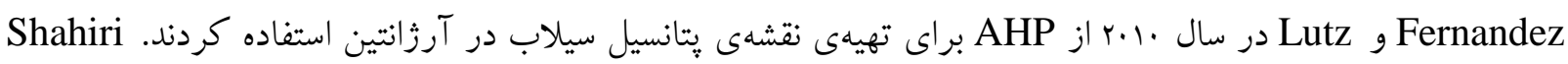

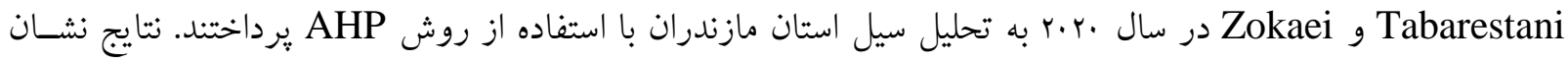

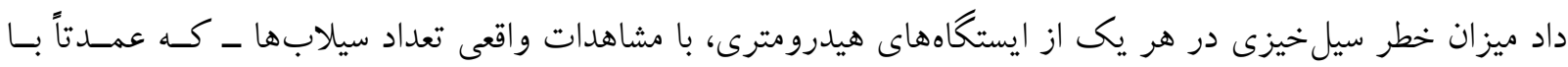

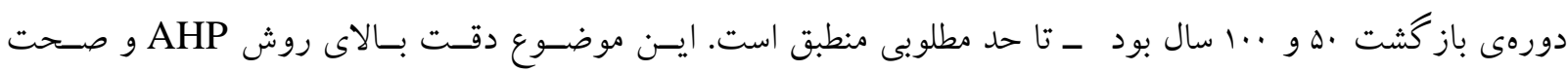

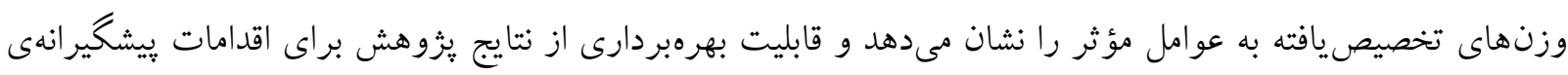
آتى را روشن مىسازد.

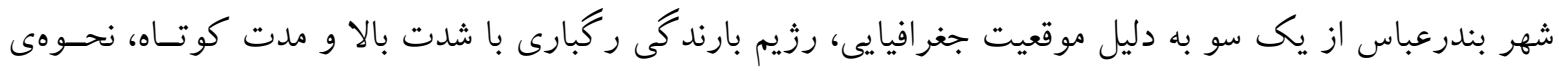

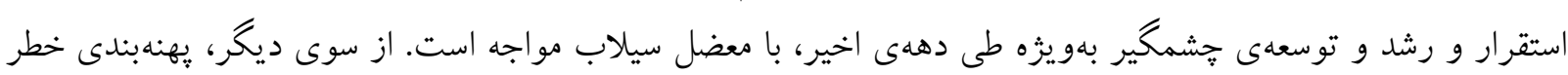

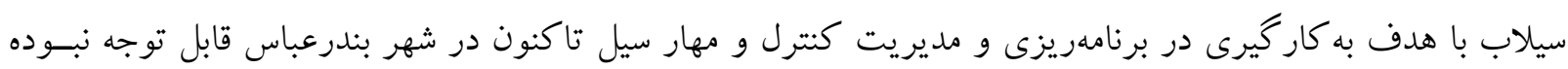

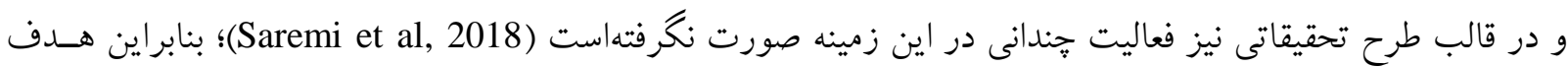

\footnotetext{
${ }^{1}$ Frequency Ratio

${ }^{2}$ Random Forest

${ }^{3}$ Fuzzy Analytic Hierarchy Process

${ }^{4}$ Index of Entropy
} 
از اين مطالعه، بررسى ريسك سيلاب شهر بندرعباس با استفاده از مدلهاى ماشين بردار پشـتيبان، بيشـينه بـىنظمسى و

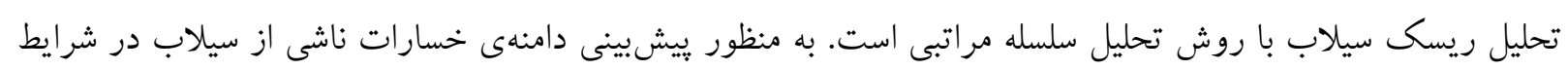
مختلف و توجيه اقتصادى و اجتماعى برنامهاى كنترل و مهار سيلاب، زههنهبندى خطر سيل ضرورى به نظر مىرســ؛ از

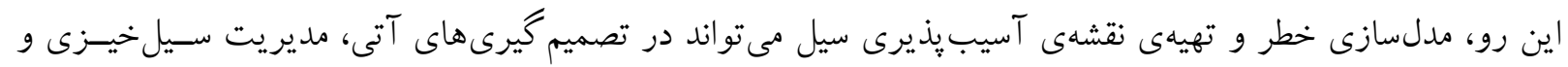

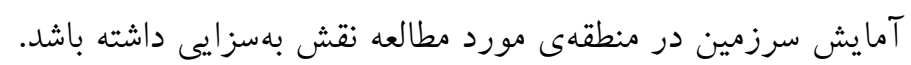

\section{rـ منطقهى مورد مطالعه}

حوزهى آبخيز شهرى بندرعباس با مساحتى بالغ بر منو كيلومترمربع، در جنوب استان هرمز كان و حاشـيهى خلـيج-

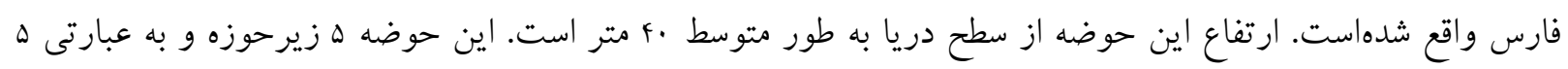

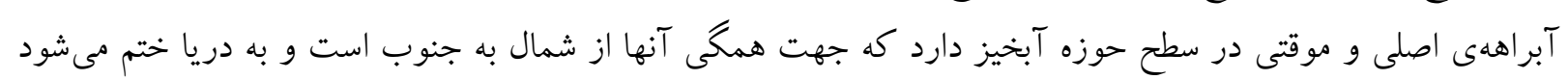

(Saremi et al, 2018)

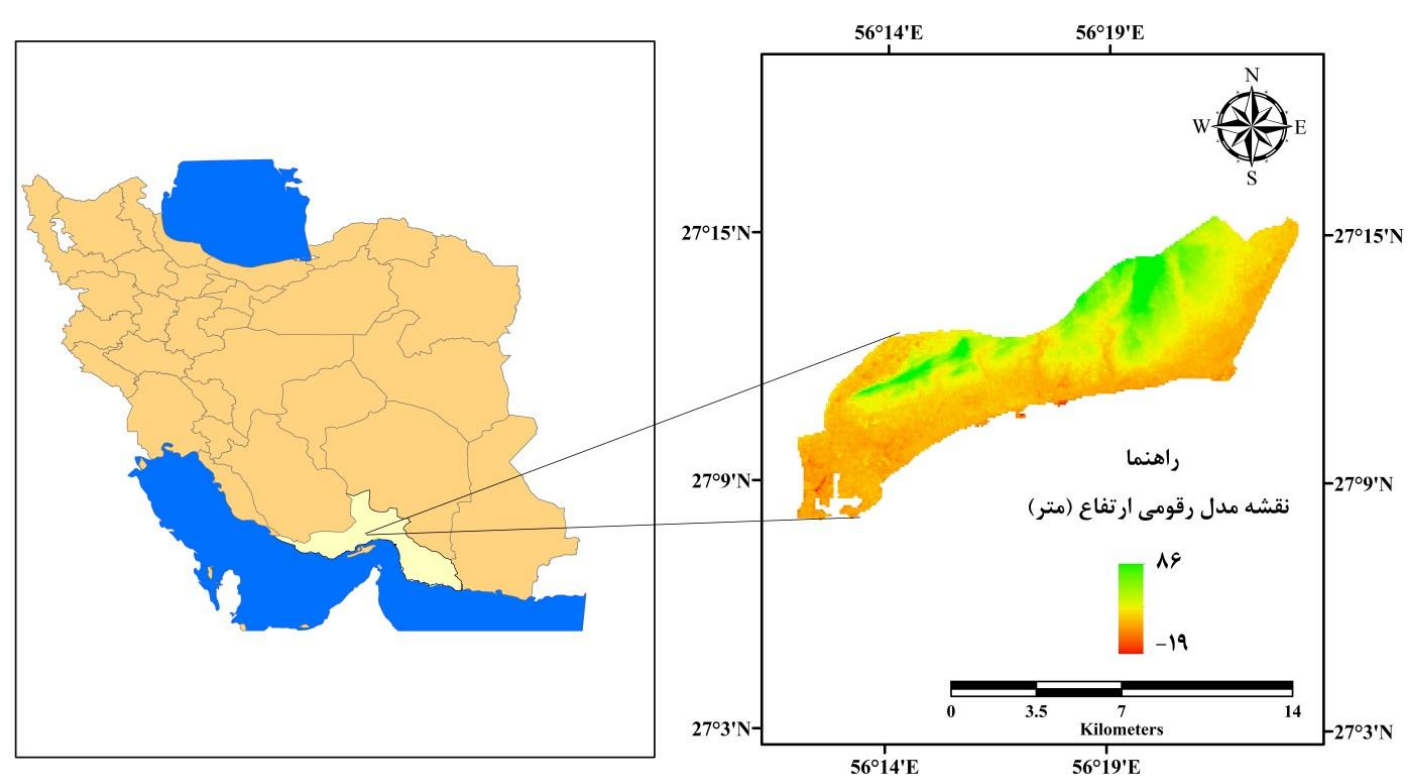

شكل ا: موقعيت منطقهى مورد مطالعه

r- مواد و روش

تحليل خطر سيل

در اين مطالعه متغيرهاى تأثير كذار مورد استفاده براى تحليل خطر سيلاب شهرى بندرعباس شـامل ارتفـاع از سـطح

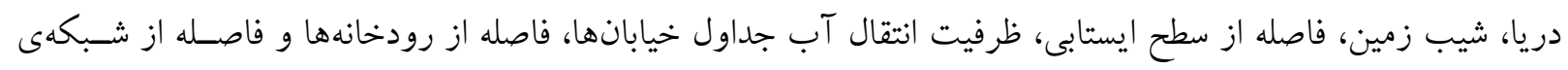

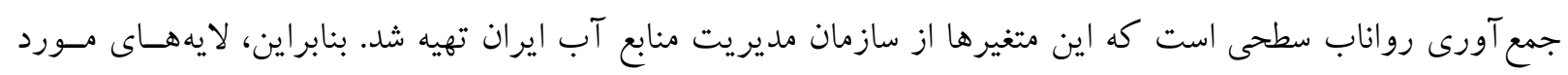

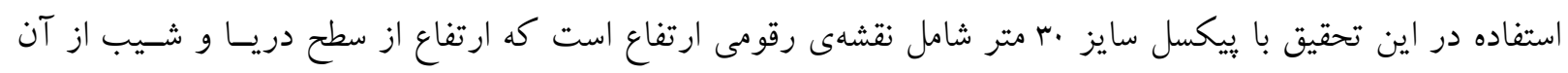

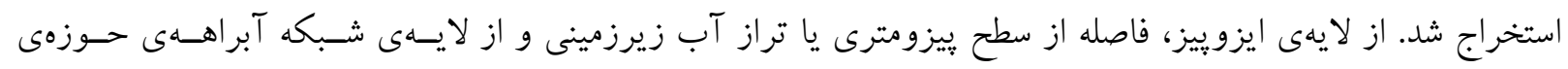

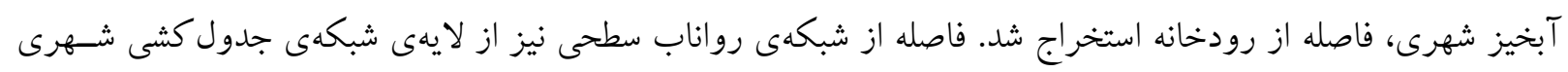




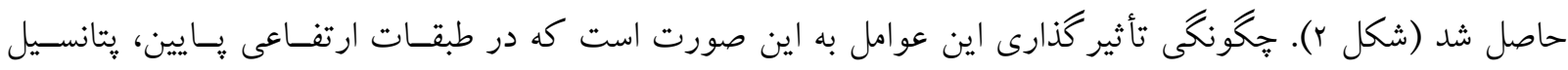

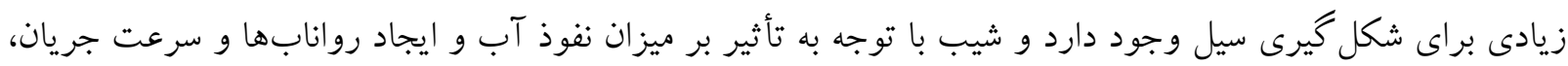

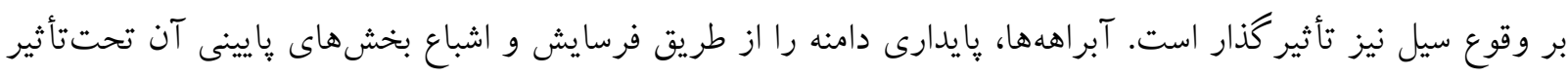

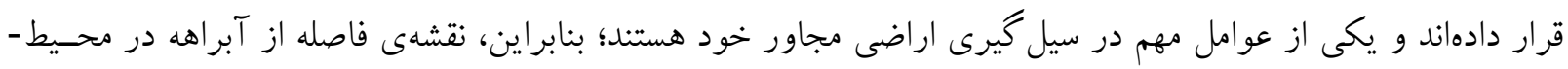
نرم|فزار ArcGIS تهيه مى شود. سطح ايستابى آب زيرزمينى نيز بر وقوع سيل و آبكرفتكى معابر تأثير دارد؛ به طورى كه در مناطق با عمق سـطح

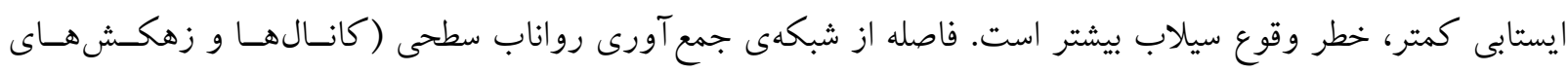

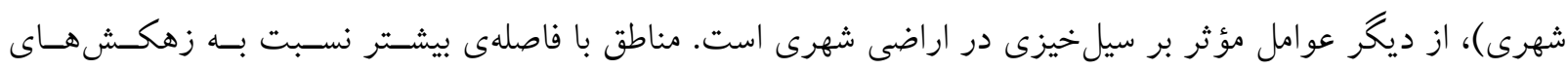

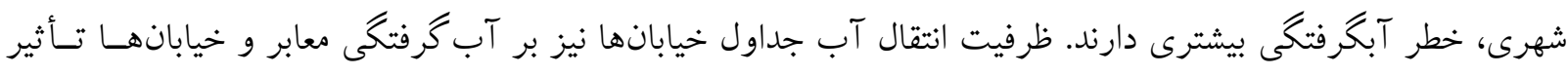

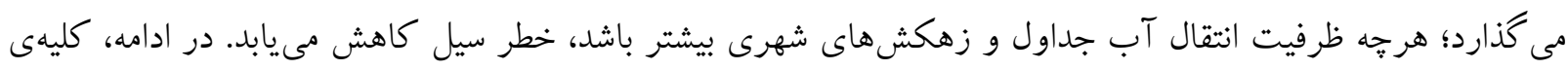

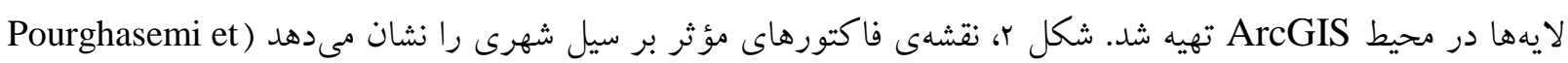
.(al, 2014 

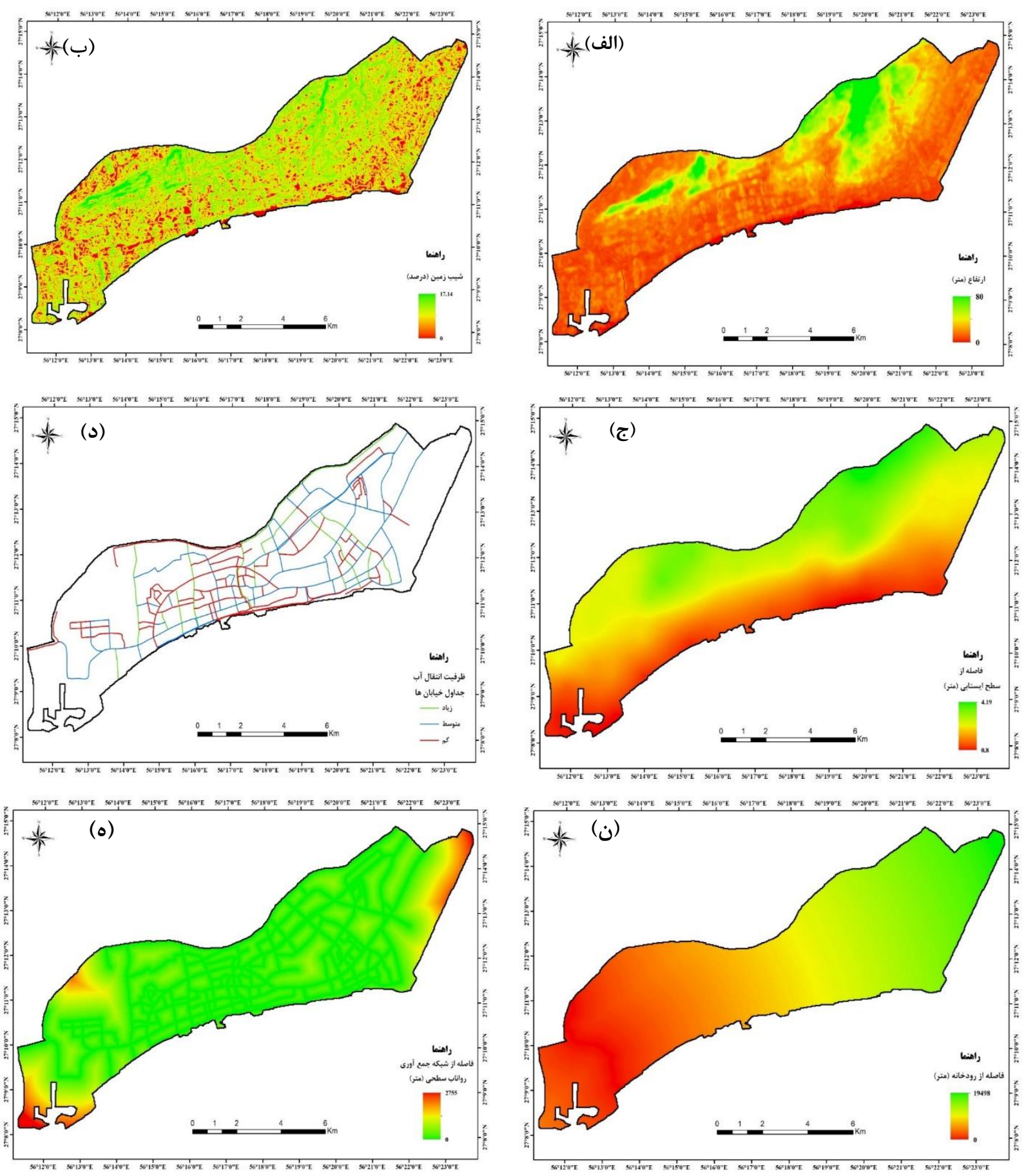

شكل r: نقشهى متغيرهاى مؤثر بر وقوع سيل الف: نقشهى ارتفاع؛ ب: شيب زمين؛ ج: فاصله از سطح ايستابى؛ د: ظرفيت انتقال آب از جدول خيابانها؛ ن: فاصله از رودخانه و ه: شبكهى فاصله از شبكه زهكثى

\section{مدلسازى خطر سيل}

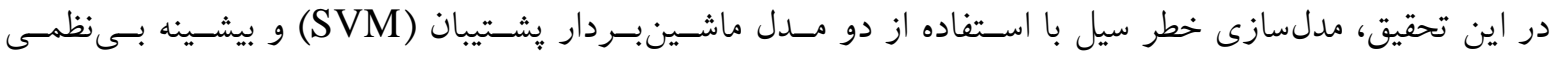
(MaxEnt) سيلاب مىتواند ابزارى مؤثر در برنامهريزى مسير توسعلى آيندهى شهر و شناخت نواحى باشد كه نيازمند توسعلى زير باري 


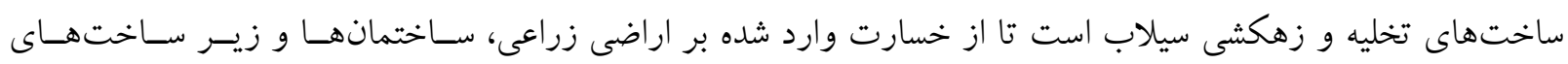
منطقهى موردنظر جلو گيرى شود.

\section{مدل ماشينبردار يشتيبان}

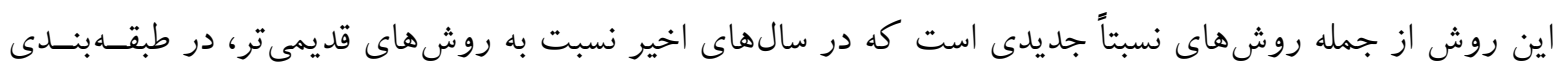

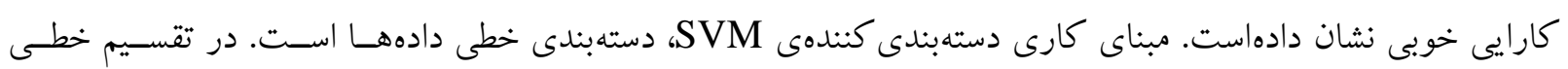

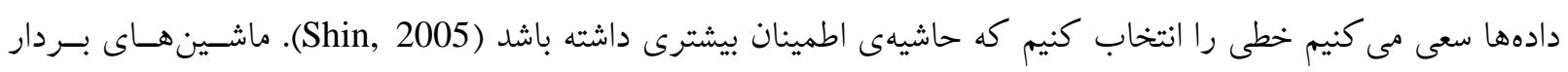
يشتيبان همانند شبكههاى عصبى مصنوعى، نوعى الكوريتم داده كاوى است. مراحل حل مسئله در اين الكوريتم، همانتســ

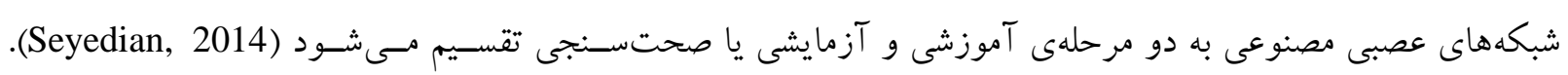

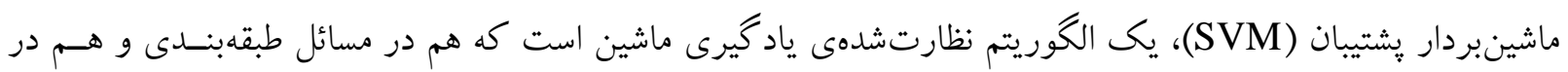

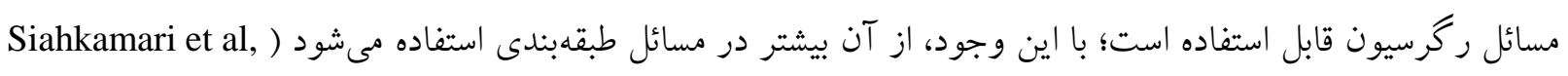

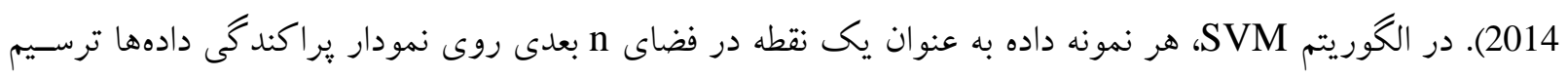

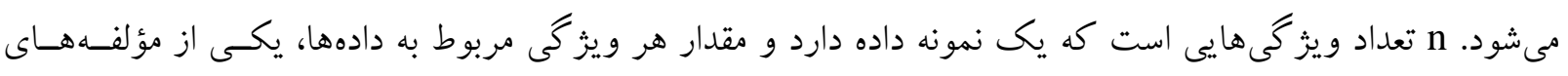

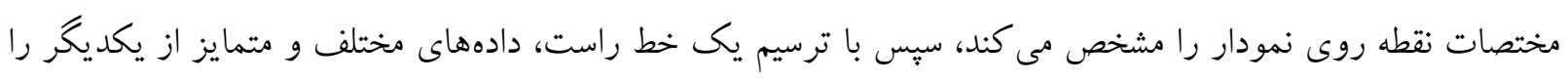
دستهبندى مى كند (Yan et al, 2018).

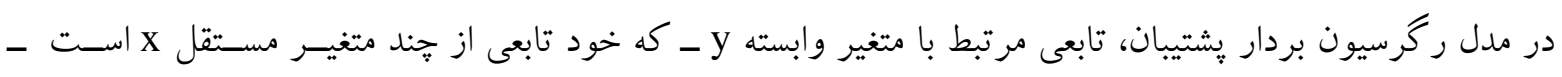

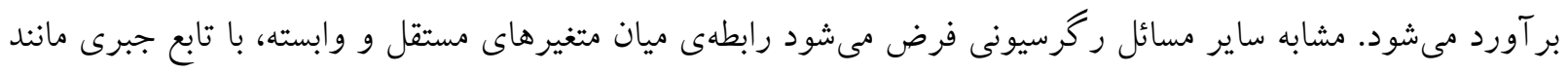

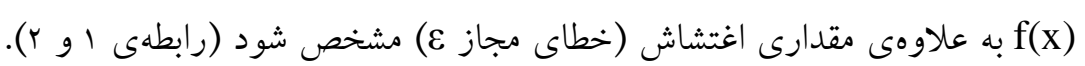

$$
f(x)=W^{T} \cdot \varphi(x)+b
$$$$
\text { رابطهى } 1
$$

$$
y=f(x)+\text { noise }
$$

رابطهى

جنانجه W بردار ضرايب، bابت مشخصهاى تابع ركرسيونى و كردن فرم تابعى براى f(x) است. اين مهم با واسنجى مدل ماشينبردار يشتيبان توسط مجموعهاى از نمونه ها (مجموعهى

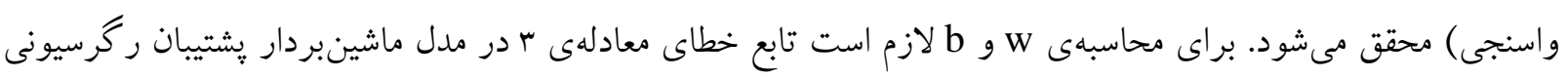

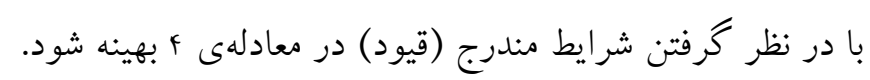
رابطهى

$$
\begin{gathered}
W^{T} \cdot \varphi\left(x_{i}\right)+b-y_{i} \leq \in+\epsilon_{i}^{*} \\
\frac{1}{2} W^{T} \cdot w+C \sum_{i=1}^{W} \epsilon_{i}+C \sum_{i=1}^{N} \epsilon_{i}^{*} y_{i}
\end{gathered}
$$




$$
\geq 0, \mathrm{i}=1,2, \ldots, \mathrm{N} \in+\mathrm{E}_{\mathrm{i}}{ }^{*} \cdot \varphi\left(x_{i}\right)-b \leq \in+\mathrm{E}_{\mathrm{i}}^{*}
$$

رابطهى ه

در معادلات بالا، C عددى صحيح و مثبت است كه عامل تعيين جريمه در هنگام رخ دادن خطاى واسنجى مسدل بـهـ

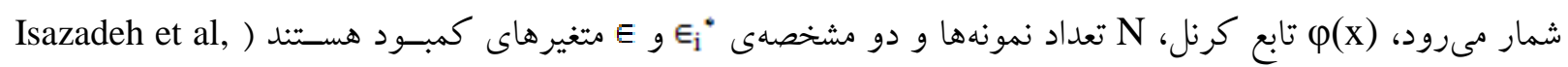

$$
\begin{aligned}
& \text { 2017). در نهايت، تابع رگرسيون بردار رشتيبان را مىتوان به فرم زير بازنويسى كرد (رابطهى \&): } \\
& f(x)=\sum_{i=1}^{N} \bar{a}_{i}, \varphi\left(x_{i}\right)^{T}, \varphi(x)+b \\
& \text { رابطهى }
\end{aligned}
$$

كه در آن

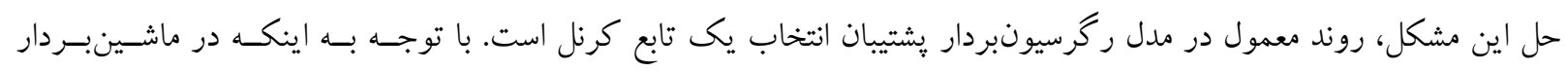

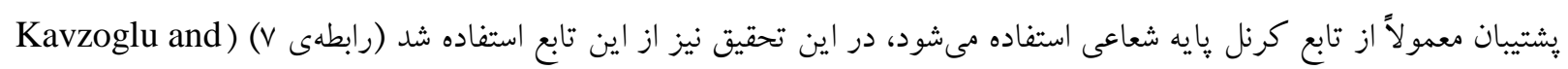

.(Colkesen, 2009

$$
k\left(x \mid x_{i}\right) \exp \left(-\frac{\left\|x-x_{i}\right\|^{2}}{\sigma^{2}}\right)
$$

رابطهى

ذكر اين امر لازم است كه فر آيند محاسبات ماشينبردار يشتيبان، بر اساس كد نويسى در محيط R انجام شد.

\section{مدل بيشينه بىنظمى}

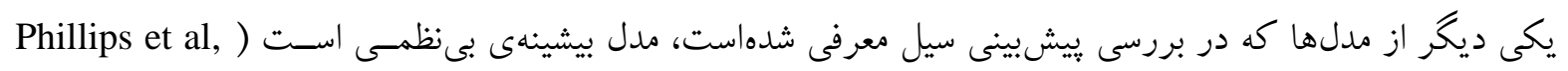

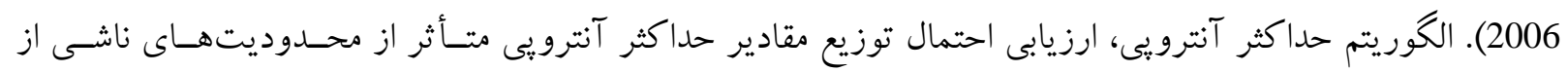

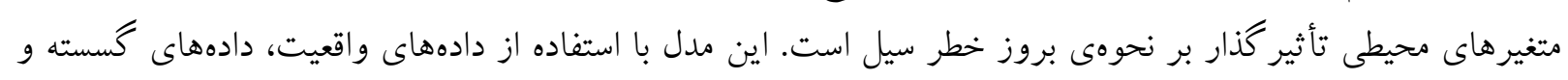

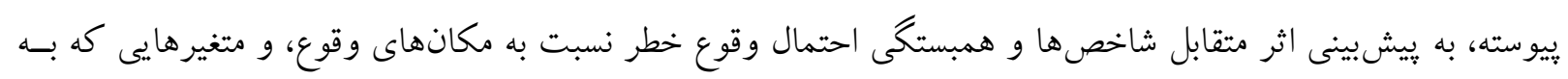

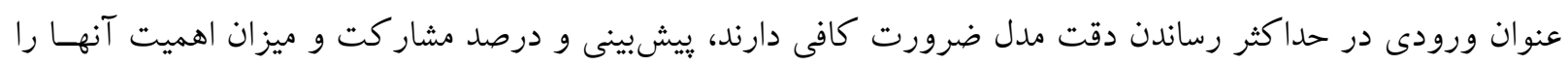
مشخص مى كند (Convertino et al, 2013). توزيع احتمال اين روش، به صورت نمايى و بر اساس تقسيم مجموع وزن وند متغيرهاى محيطى بر يكى مقياس ثابت بر آورد مىشود؛ به طورى كه مقادير احتمال بين صفر و يكى قرار مسى گيــرد و

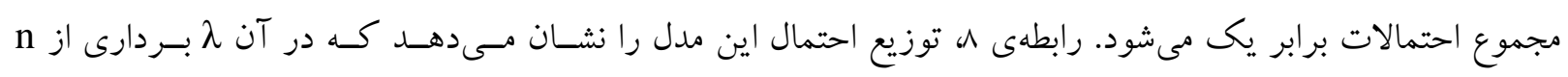

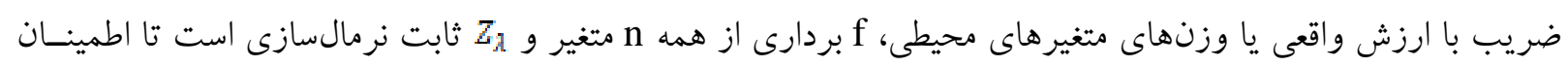
حاصل شود كه مجموع גه برابر يك مى شود (Rezaei et al, 2017).

$$
q_{\lambda}(x)=\frac{e^{\lambda \cdot f(x)}}{Z_{\lambda}}
$$

رابطهى 
آزمون جك نايف نيز نوعى روش تعيين اهميت متغيرها به روش جايگزين در مدلهاى بيشبينى است كه به روش

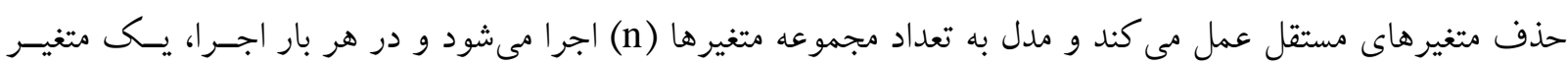

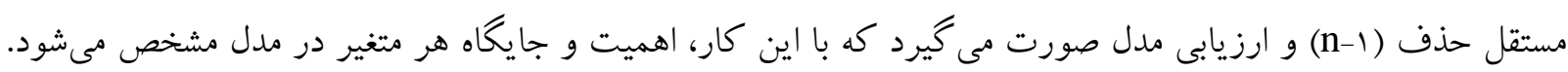

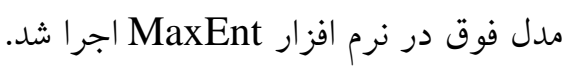

\section{ارزيابى مدلها}

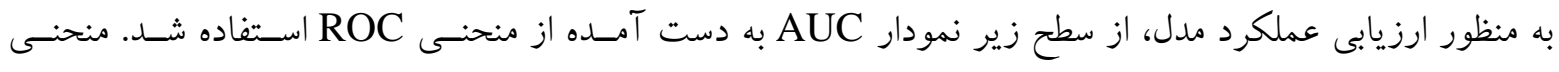

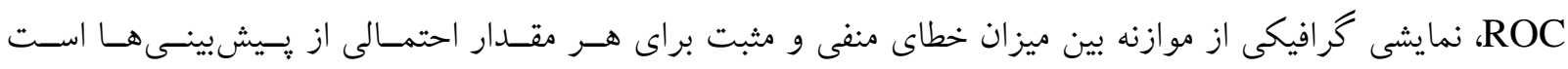

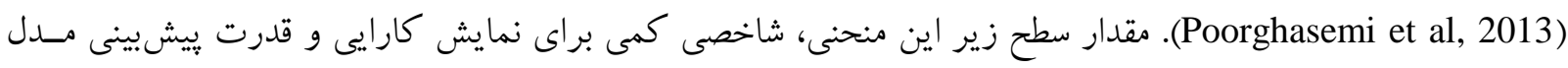

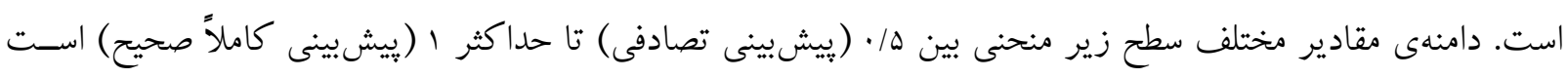

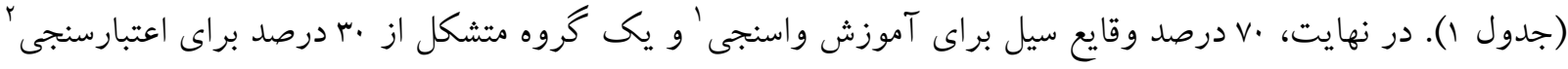
تقسيم شد.

\begin{tabular}{|c|c|}
\hline مقادير سطح زيرمنحنى (AUC) & دقت يِشينى \\
\hline$\cdot / 9-1$ & 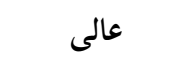 \\
\hline$\cdot / 1 \Lambda_{-} \cdot / 9$ & خيلى خوب \\
\hline$\cdot / V-\cdot / \Lambda$ & خوب ل \\
\hline$\cdot / \varepsilon_{-} \cdot / V$ & 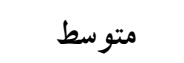 \\
\hline$\cdot / \Delta-\cdot / 8$ & ضعيف \\
\hline
\end{tabular}

تحليل آسيب يذيرى سيلاب

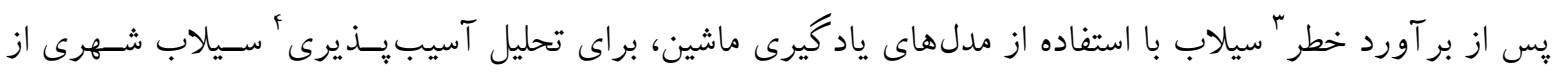
ديخر فاكتورهاى مؤثر تحت عنوان فاكتورهاى غيرمحيطى و ادافيكى شامل وضعيت اقتصادى ـ اجتماعى منطقه، تـراكم

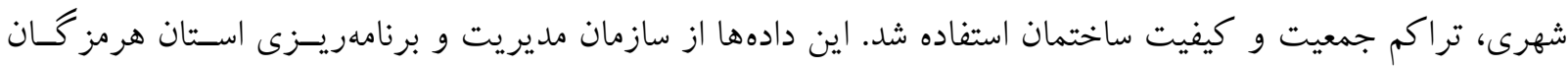

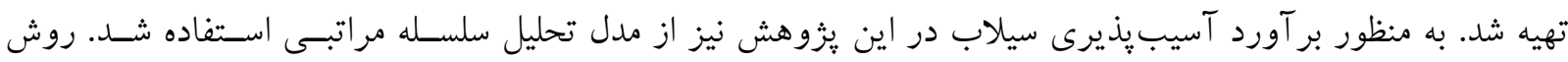
AHP

\footnotetext{
${ }^{1}$ Training

${ }^{2}$ Validatio

${ }^{3}$ Risk

${ }^{4}$ Vulnerability
} 


\section{تشكيل ساختار سلسله مراتبى}

طرح يرسشنامه و جمع آورى نظرات كارشناسان مختلف در مورد ميزان اهميت و ارزش هر كدام از معيارها نسـبت به تعيين هدف با توجه به جدول و كميتى ساعتى صورت گرفت. جدول r، مقياس و كميتى ساعتى را نشان مى دهد.

جدول Y : مقياس q كميتى ساعتى براى مقايسهى دودويى معيارها (بلداجى و همكاران، IMAq)

\begin{tabular}{|c|c|}
\hline تعريف & 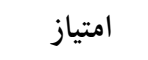 \\
\hline اهميت مساوى در تحقق هدف دو معيار اهميت مساوى دارند. & 1 \\
\hline اهميت اندكى بيشتر براى تحقق هدف اهميت i بيشتر از j است. & $r$ \\
\hline اهميت بيشتر اهميت i خيلى بيشتر از j است. & $\Delta$ \\
\hline اهميت خيلى بيشتر اهميت i خيلى خيلى بيشتر از j است. & V \\
\hline اهميت مطلق اهميت خيلى بيشتر i نسبت به j به طور قطعى به اثبات رسيدهاست. & 9 \\
\hline هنگامى كه حالت هاى ميانه وجود دارد. & $r_{6} F_{6} G_{6} \Lambda$ \\
\hline
\end{tabular}

تشكيل ماتريس مقايسلى زوجى معيارها

محاسبهى ميانكين هندسى هر سطر از ماتريس مقايسهى زوجى (bij) رابطهى 9. $b i j=\left(\prod_{i=1}^{k} a_{i j}\right)^{\frac{1}{k}}$

9 رابطهى

مانيانگ Bij ميانين هندسى هر سطر از ماتريس مقايسهى زوجى، a اهميت معيار أlم نسبت به معيار زام نرمـاليزه كـردن

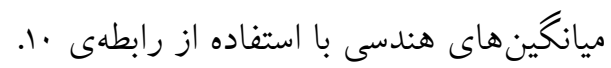
$w_{i}=\frac{a_{i j}}{\sum_{i=1}^{k} b_{i j}}$

1. رابطهى

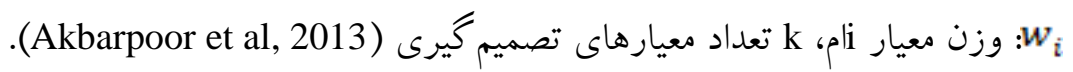

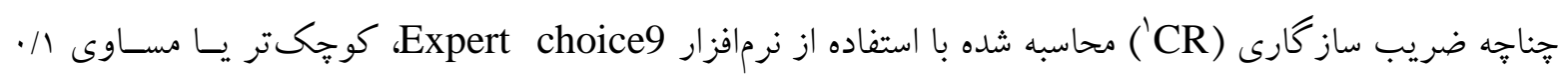
باشد، ساز گارى در قضاوتها مورد قبول است؛ در غير اين صورت، بايد در قضاوتها تجديد نظر شود. بنابراين، در اين يزوهش ابتدا شاخصهاى مؤثر بر سيلخيزى شهر بندرعباس از طريق مطالعات و تجربهى كارشناسى تعيين شـد؛ بــدين منظور بر اساس مطالعات جغرافيايى و سوابق سيلاب در اين شهر، متغيرهاى وضـعيت اقتصـادى ــ اجتمـاعى، تـراكم شهرى، تراكم جمعيت و كيفيت ساختمان به عنوان متغيرهاى اصلى تأثير كذار بر افزايش آسـيبيـذيرى سـيلاب، بـهـ كارشناسان معرفى و از آنها خواسته شد كه تقدم اولويت خطر را به صورت زوجى به روش سلسله مراتبى و مقياس اتنات

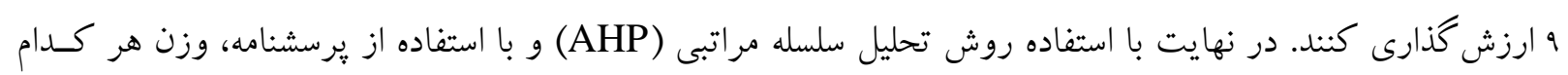

\footnotetext{
${ }^{1}$ Consistency Ratio
} 
از شاخص هاى مورد استفاده تعيين شد. با توجه به ورودى لايههاى مختلف با درجهبندى هاى متفاوت و نياز به يكسـان-

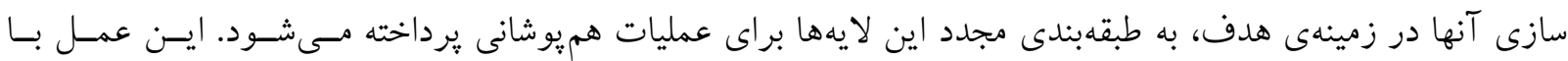

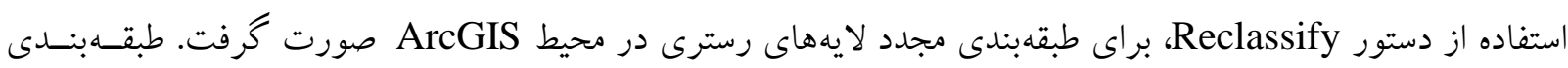

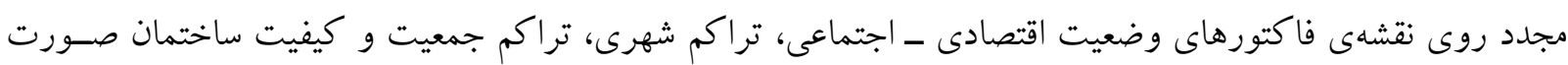

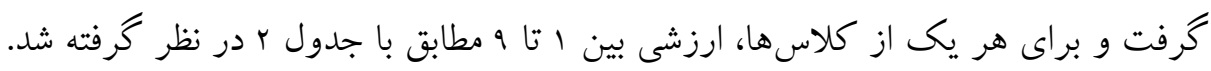

\section{ارزيابى ريسك سيل}

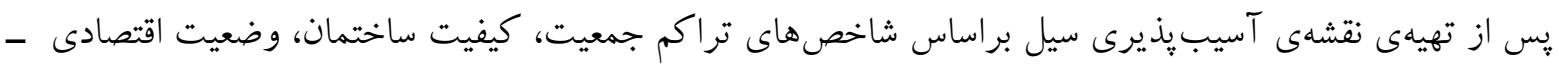
اجتماعى و تراكم شهرى (براساس مدل AHP) و تهيهى نقشهى خطر سيل براساس شاخص هاى ارتفاع از سـطح دريـا،

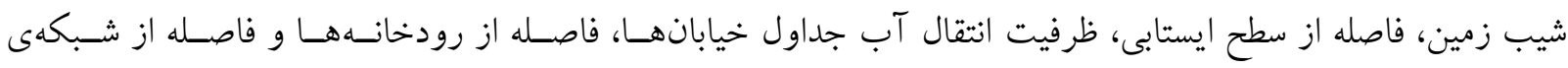

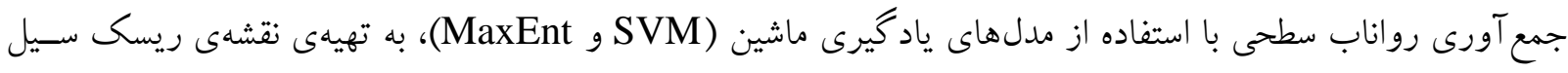

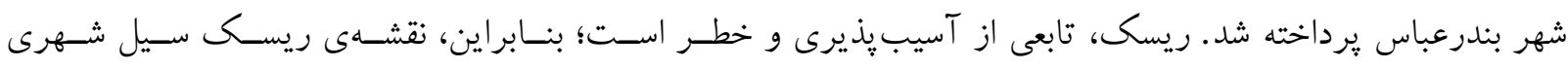
بندرعباس براساس تلفيق نقشهاى آسيبذيذيرى و خطر با استفاده ازمعادلهى زير به دست آمد (Dewan, 2013):

\section{Risk = Hazard $\times$ Vulnerability}

F نقشهى توزيع مكانى وقايع آبخرفتخى در شكل (r الف) نشان داده شدهاست. در كـل، هو موقعيـت آبكرفتخـى در

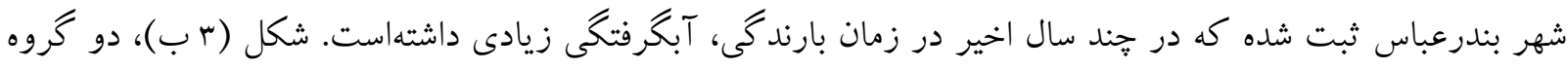

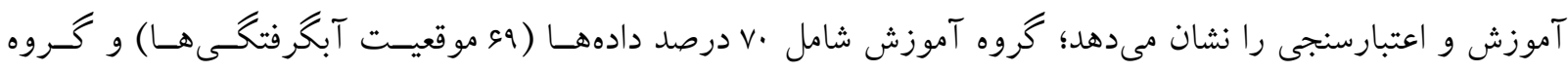

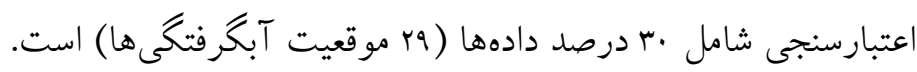

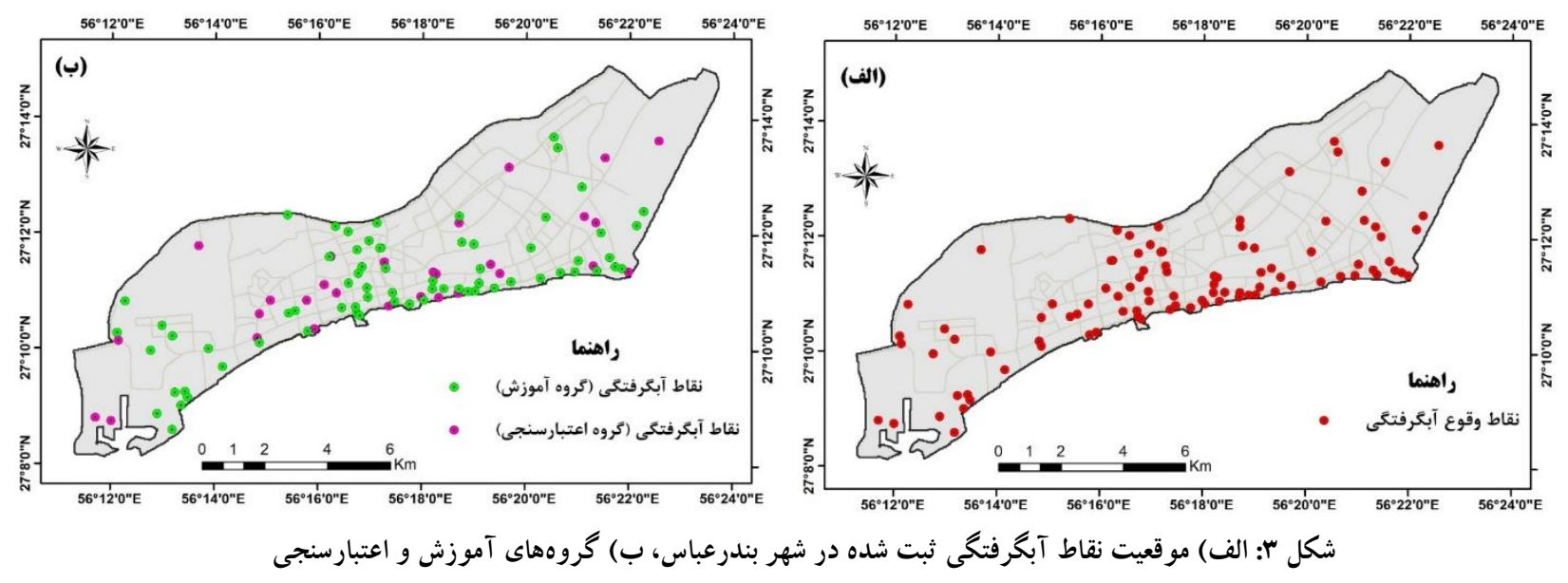

نقشهى ييشبينى احتمال وقوع خطر آبكرفتكى براساس مدل بيشينه بىنظمى در شكل († الف) نشان داده شدهاست.

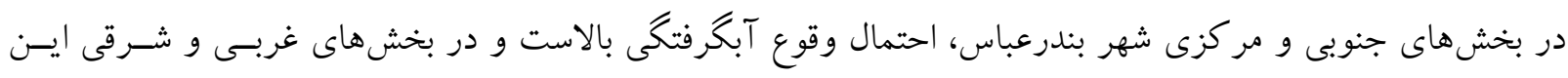

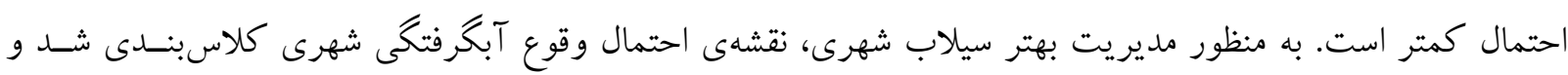


اين كلاسها براساس مدل بيشينه بىنظمى در شكل (f ب) نشان داده شد. كلاسهاى پتانسيل آبگرفتخى زياد و خيلى

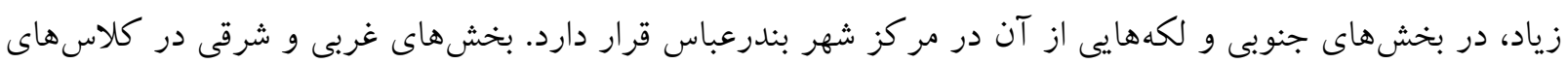

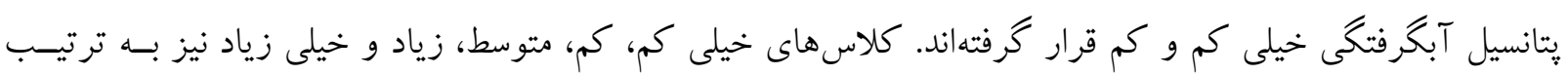

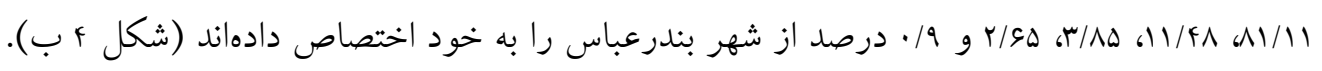
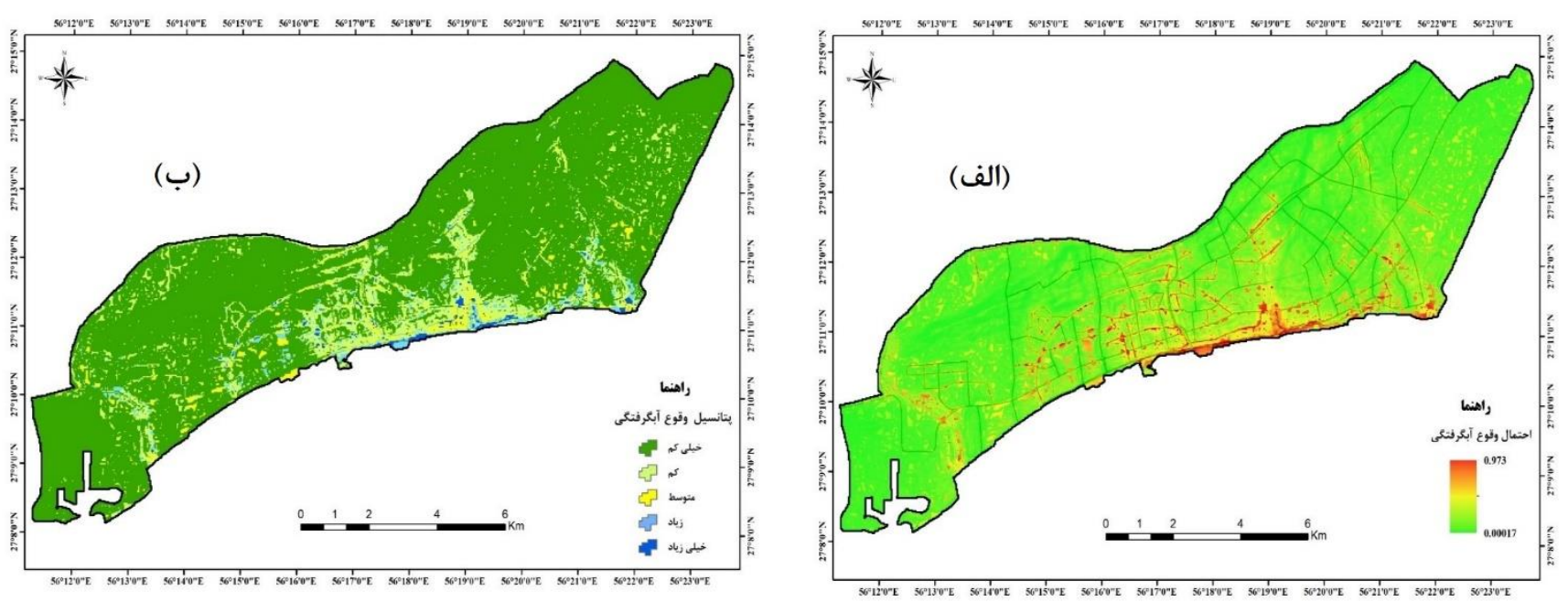

شكل f: الف) نقشه احتمال وقوع آبكر فتخى با استفاده از مدل بيشينه بىنظم، ب) نقشه كلاسهاى يتانسيل وقوع آبحر فتكى با استفاده از مدل بيشينه

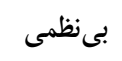

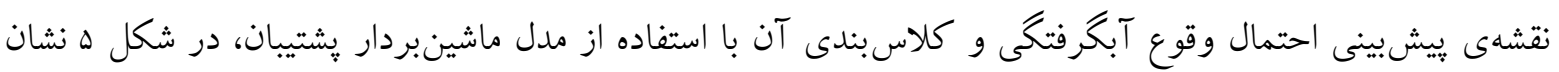

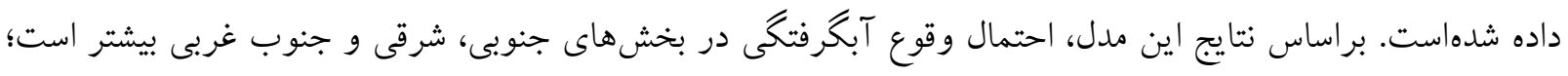

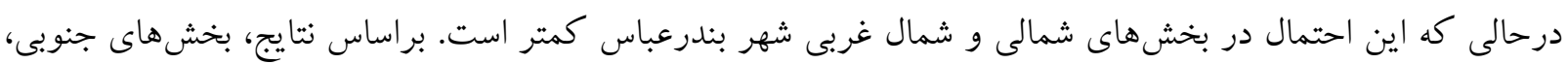

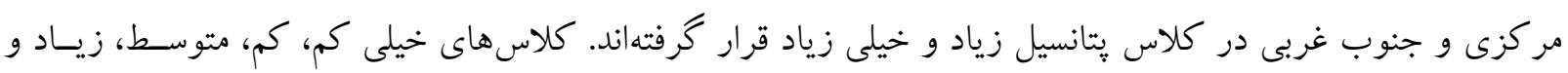

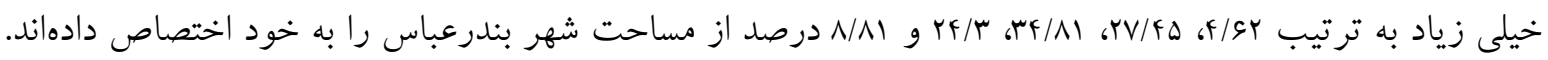
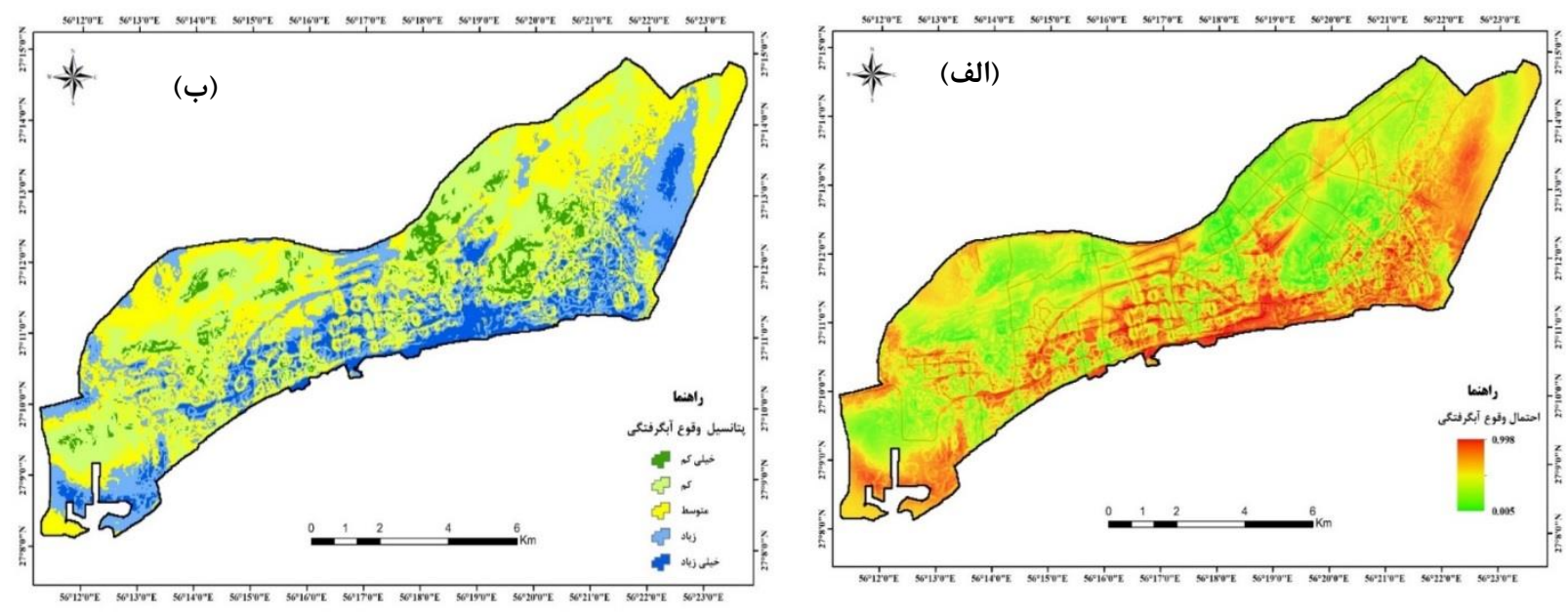

شكل ه: نقشهى احتمال وقوع آبكر فتخى (الف) و كلاسبندى (ب) با استفاده از مدل ماشينبردار קشتيبان 
براى تعيين دقت مدلها، از معيار مساحت زير منحنى مشخصهى عامل گيرنده استفاده شد. شكل \&، ميزان دقت مـدل

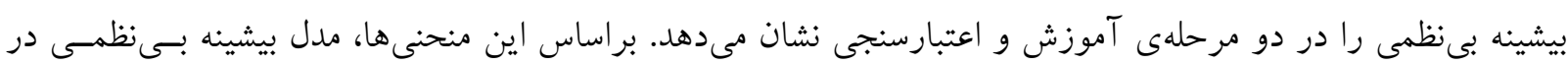

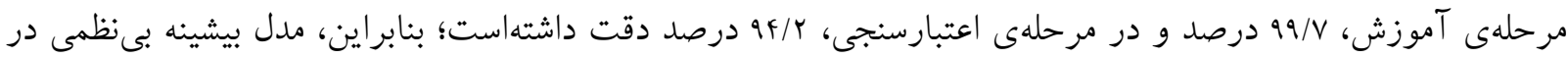
هر دو مرحلهى آموزش و اعتبارسنجى، كارايى عالى (مساحت زير منحنى بالاتر از •و درصد) داشتهاست.

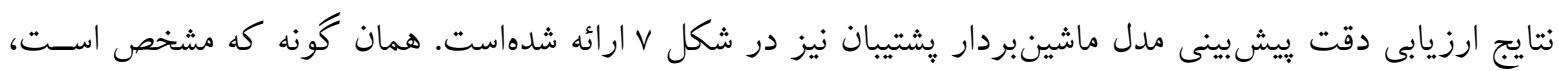

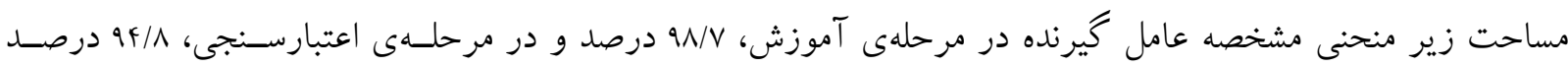
است. بنابراين، مدل ماشينبردار يشتيبان عملكرد عالى دارد؛ زيرا در هر دو مرحلهى آموزش و اعتبارسـنجى، مسـاحت زير منحنى بيش از ·9 درصد بودهاست.
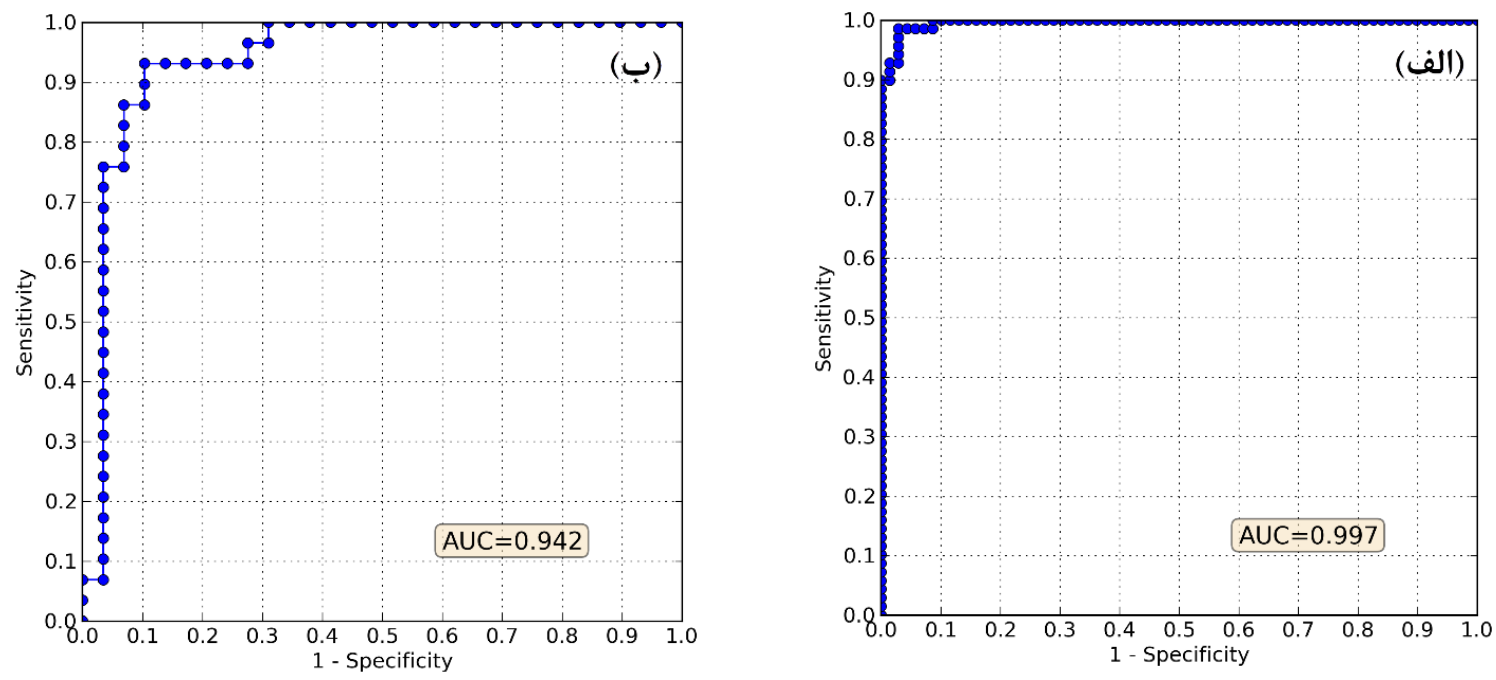

شكل \&: منحنى مشخصه عامل گيرنده به دست آمده از مدل بيشينه بىنظمى در مراحل آموزش (الف) و (ب) اعتبارسنجى
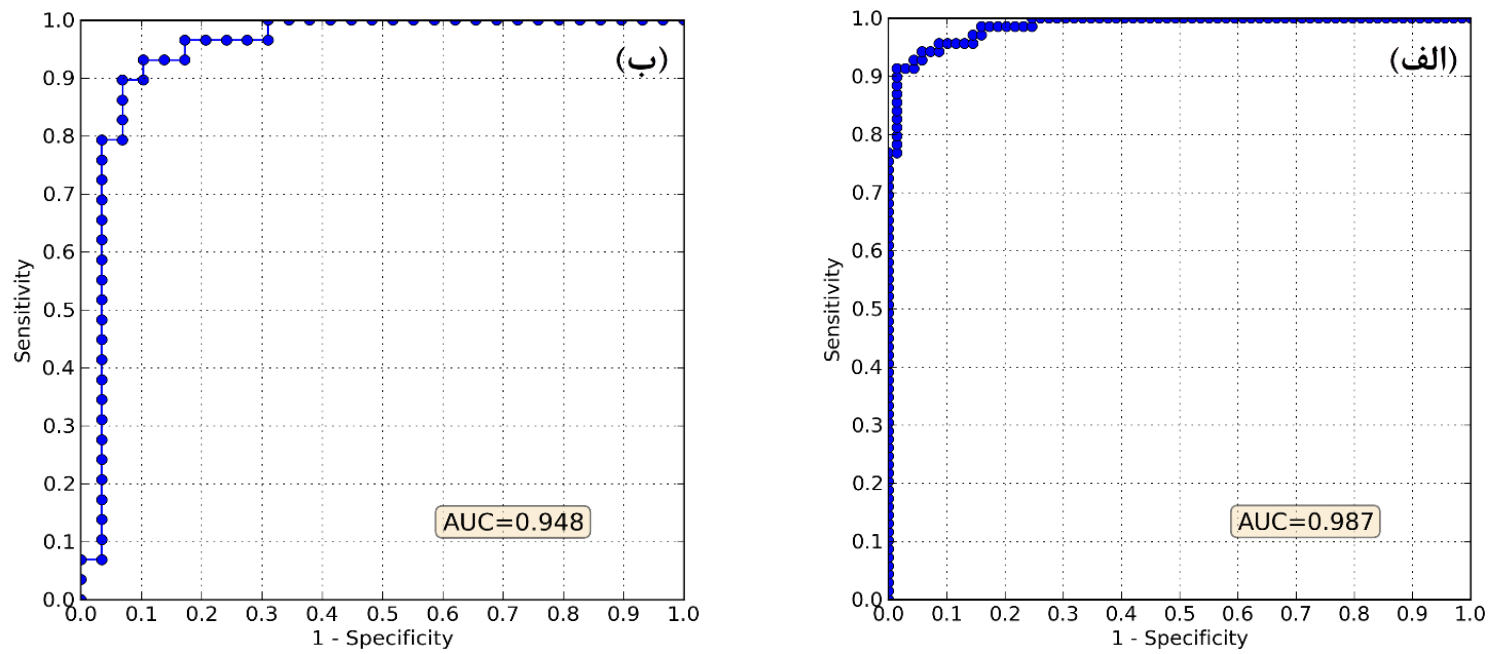

شكل V: منحنى مشخصه عامل گيرنده به دست آمده از مدل ماشينبردار بشتيبان در مراحل آموزش (الف) و (ب) اعتبارسنجى

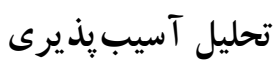

هدف از تحقيق حاضر با توجه به موارد بيشتر كفته شده، تحليل ريسك سيلاب است؛ از اين رو، علاوه بر تحليـل

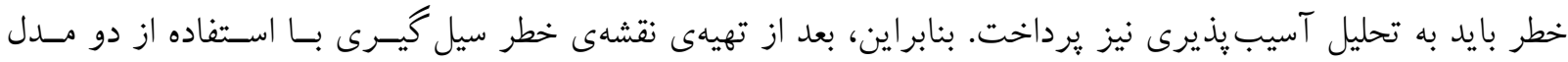


ياد كيرى ماشين، مرحلهى بعدى تحليل آسيب يذيرى با استفاده از شاخصهـاى غيرمحيطى اسـت. در بررسىى تحليـل

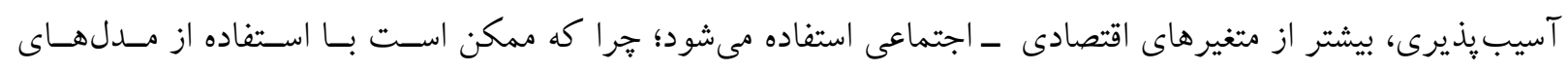

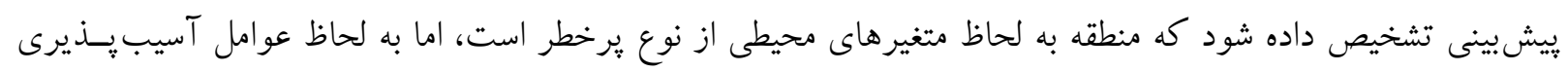

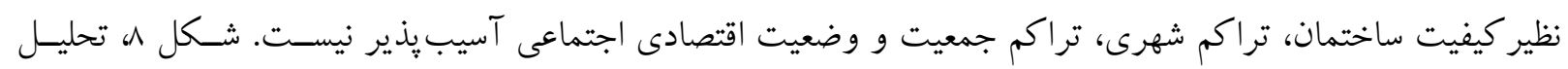

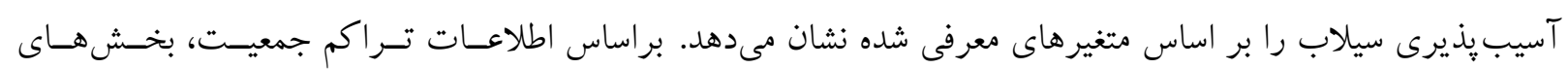

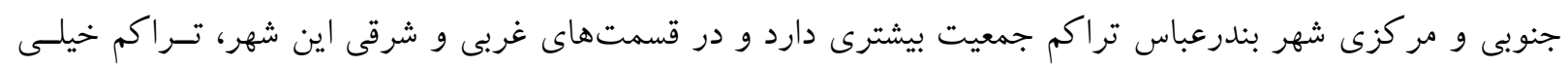

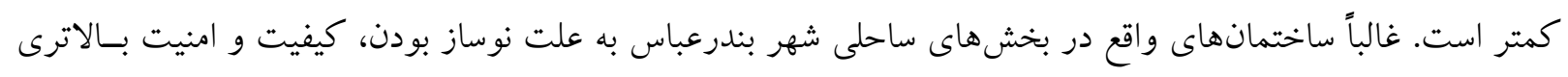
دارد. از طرفى، بخشهاى جنوب غربى و شمال شرقى داراى ساختمانهايى سنتى با كيفيت پايينتر است. براساس آمار

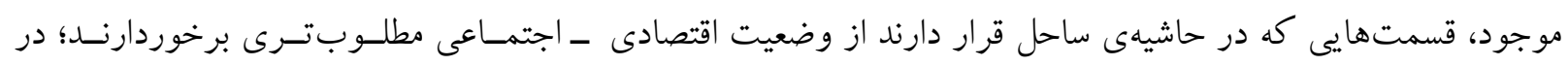
قسمتهاى شمالى، غربى و جنوبى نيز وضعيت اقتصادى ـ اجتماعى مردم ضعيفتر است. در بخش جنوبى اين شهر بــه

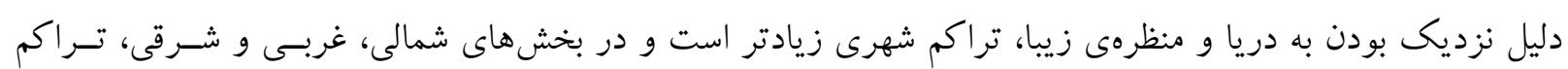
شهرى كمتر. امتياز كلاسهاى عوامل مؤثر بر آسيب: بذيرى، در جدول r نشان داده شدهاست. كلاس تراكم جمعيت خيلى زيـاد، كلاس كيفيت ساختمان كم، كلاس اقتصادى ـ اجتماعى ضعيف و تراكم شهرى خيلى زياد داراى بيشترين امتياز است.

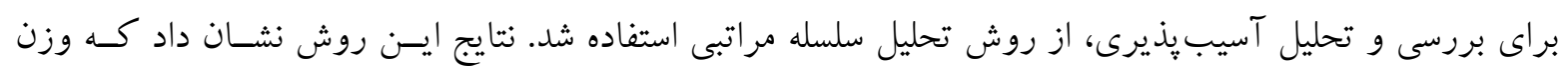

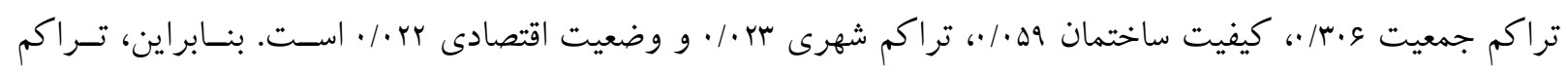
جمعيت مهمترين معيار مؤثر بر آسيب پيذيرى است. كيفيت ساختمان، تراكم شهرى و وضعيت اقتصادى ــ اجتماعى بـه

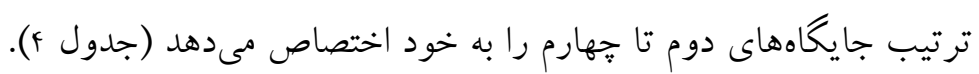
نقشهى درجهى آسيبٍٍيرى شهر بندرعباس براساس نتايج روش تحليل سلسله مراتبى، در شكل (9 الف) نشان داده

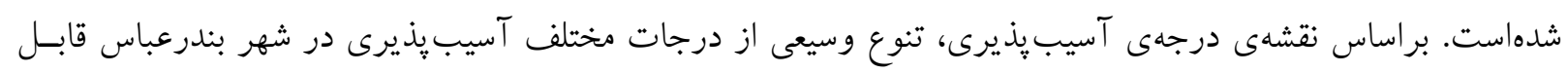

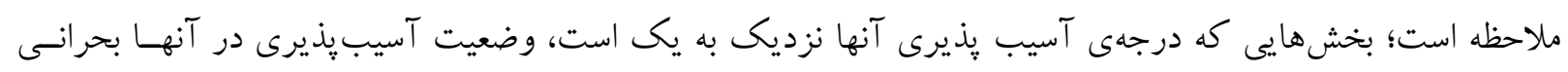

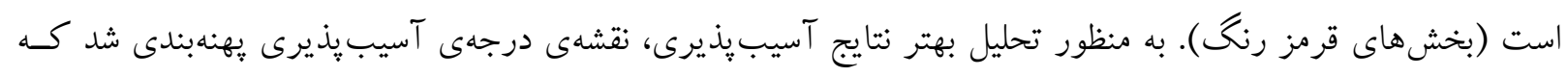

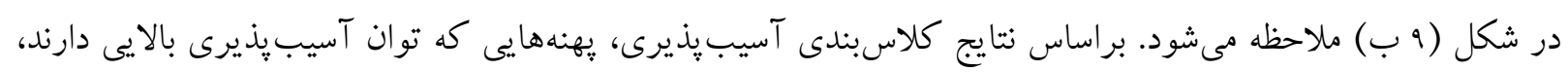

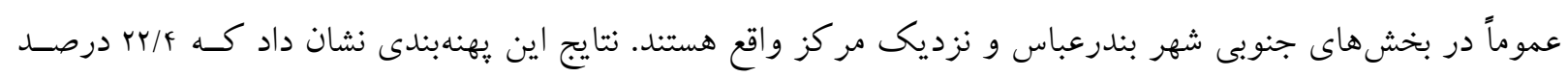

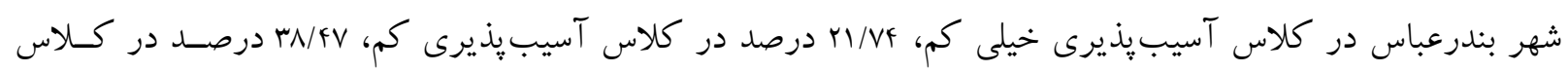

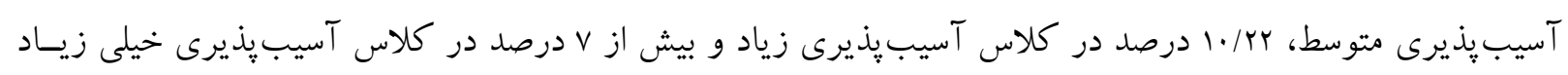
قرار گرفتهاند. 

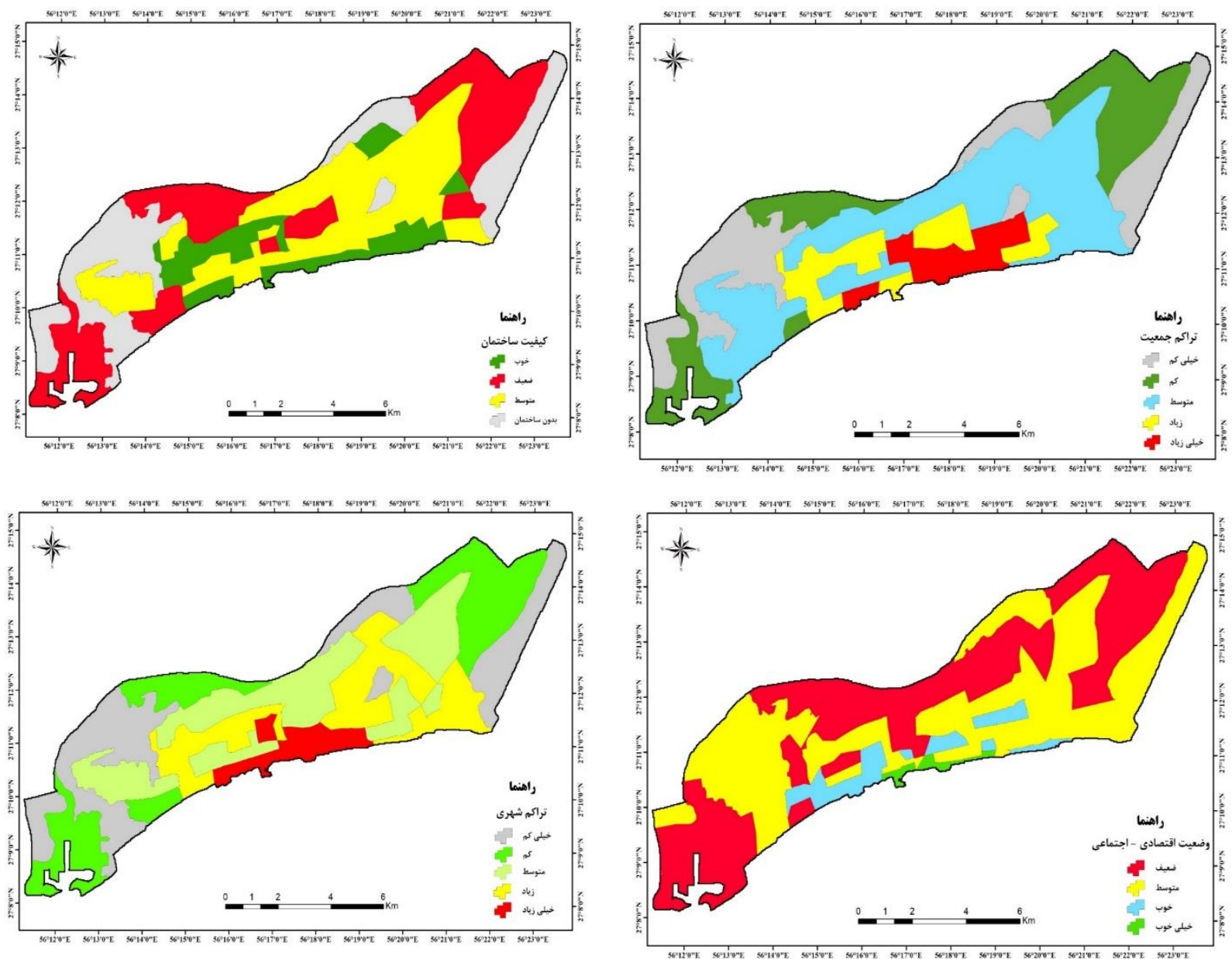

شكل ^: نقشهى عوامل مؤثر در تحليل آسيب يذيرى 


\begin{tabular}{|c|c|c|}
\hline امتياز & كلاس & فاكتور \\
\hline 1 & خيلى كم & تراكم جمعيت \\
\hline r & كم & \\
\hline r & متوسط & \\
\hline f & زياد & \\
\hline$\Delta$ & خيلى زياد & \\
\hline . & بدون ساختمان & كيفيت ساختمان \\
\hline r & ك & \\
\hline r & متوسط & \\
\hline 1 & زياد & \\
\hline f & ضعيف & اقتصادى و اجتماعى \\
\hline$r$ & متوسط مت & \\
\hline r & خوب & \\
\hline 1 & خيلى خوب & \\
\hline 1 & خيلى كم & تراكم شهرى \\
\hline r & كم & \\
\hline$r$ & متوسط & \\
\hline f & زياد & \\
\hline$\Delta$ & خيلى زياد & \\
\hline
\end{tabular}

جدول †: نتايج مقايسهى زوجى معيارهاى مؤثر بر آسيبذيذيرى

\begin{tabular}{|c|c|c|c|c|c|}
\hline 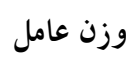 & وضعيت اقتصادى ـ اجتماعى & تراكم شهرى & كيفيت ساختمان & تراكم جمعيت & عوامل \\
\hline$\cdot / r \cdot s$ & $a$ & $\varepsilon$ & v & 1 & تراكم جمعيت \\
\hline .1 .09 & r & r & 1 & & كيفيت ساختمان \\
\hline $1 \cdot \pi \mu$ & 1 & 1 & & & تراكم شهرى \\
\hline.$/ \cdot r r$ & 1 & & & & وضعيت اقتصادى ـ اجتماعى \\
\hline & & اع/ع درص & & & ميزان ساز كارى (CR) \\
\hline
\end{tabular}



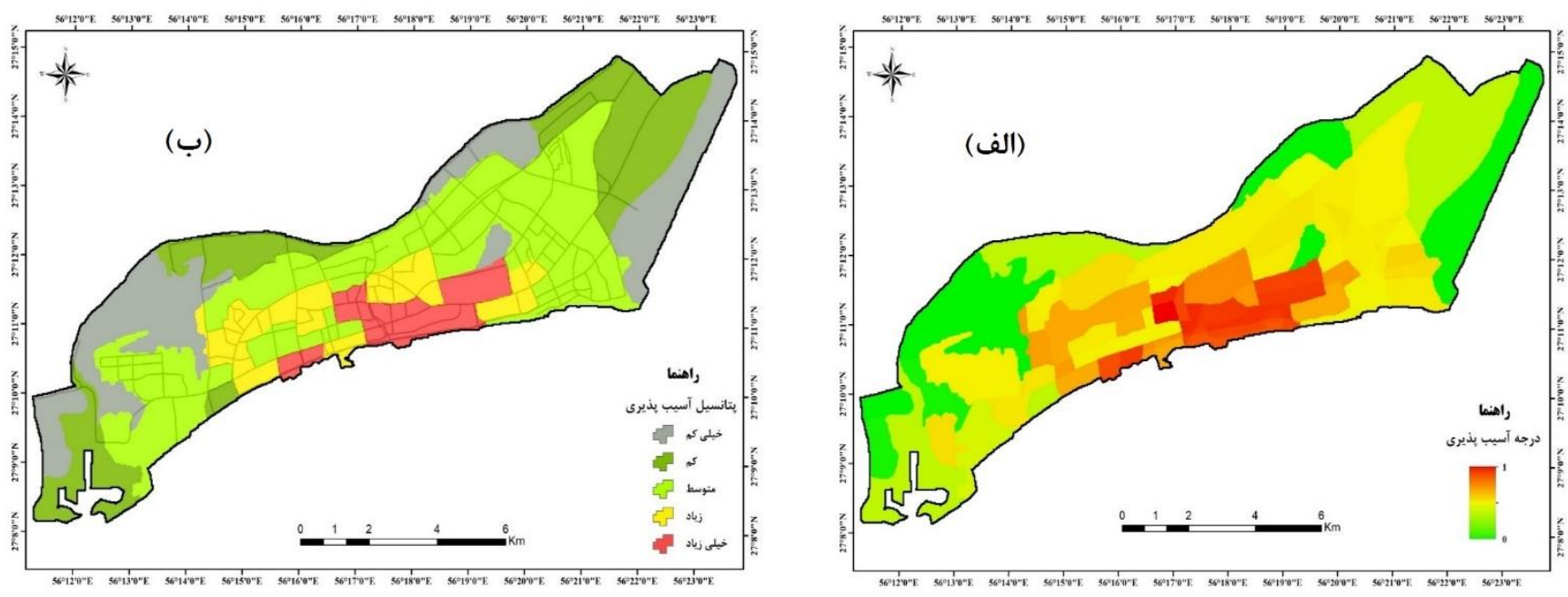

شكله: الف) نقشهى توزيع مكانى درجه آسيبذيذيرى شهر بندرعباس نسبت به سيل ب) نقشهى يهنهبندى پيتانسيل آسيب يذيرى شهر بندرعباس

با در نظر كرفتن ميزان خطر و درجهى آسيب يذيرى، نقشهى ريسك آبكرفتكى تهيه شد كـه در شـكل (.ا الـف)

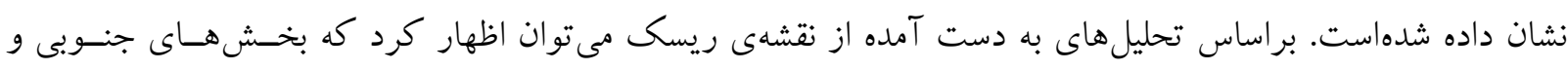

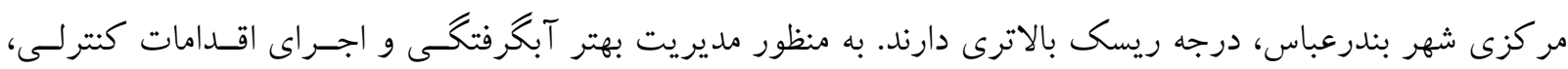

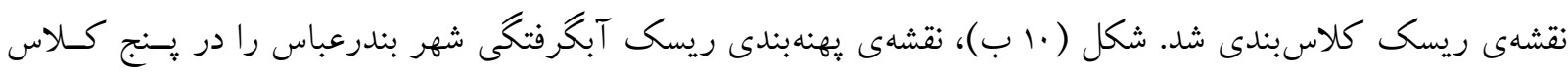

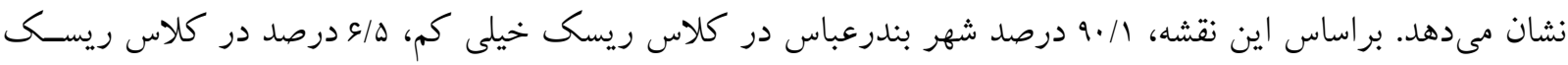

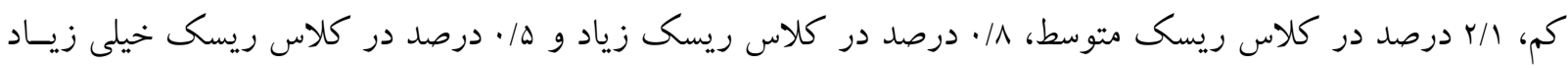

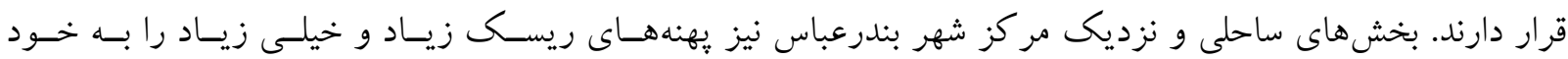
اختصاص دادهاند. همجنين بخشهاى شمالى، غربى و شرقى نيز به عنوان كلاسهاى ريسك خيلى كم تا ريسك متوسط شناسايى شد.
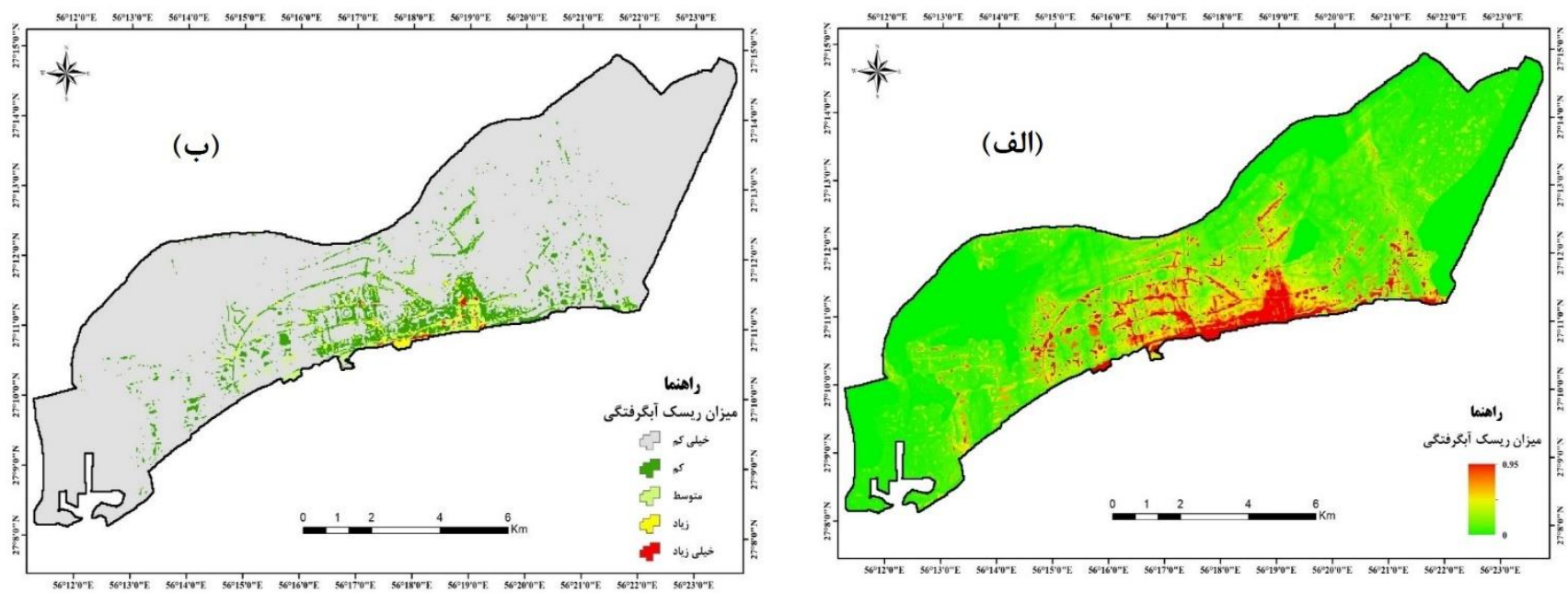

شكل • ا: الف) نقشه توزيع مكانى درجلى ريسى آبخرفنتى ب) نقشهى يهنهبندى ريسك آبكر فتخى شهر بندرعباس 
در اين تحقيق خطر آسيبيذيرى، ريسك آبكرفتكى و سيلاب شهرى بندرعباس با اسـتفاده از دو مـدل يـادگيرى

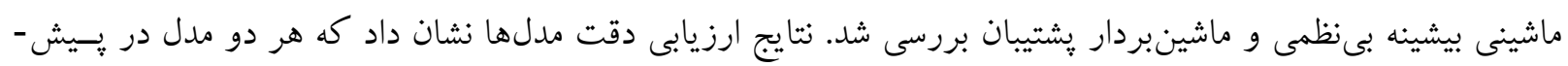

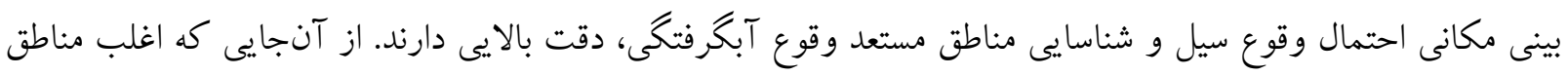

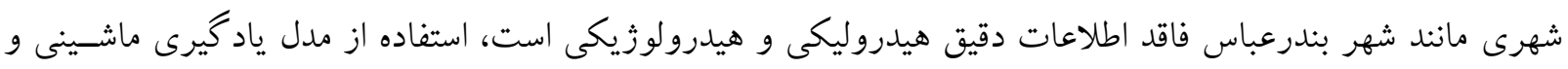

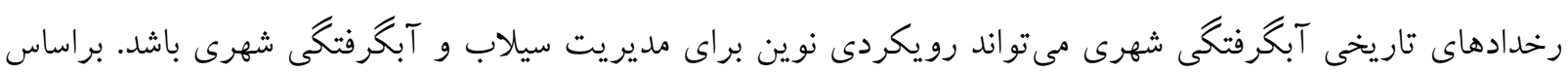

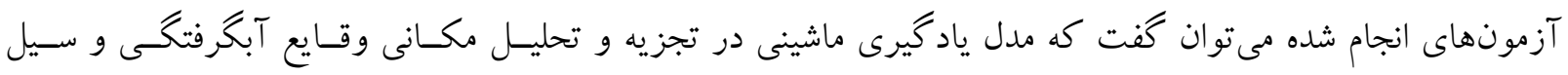

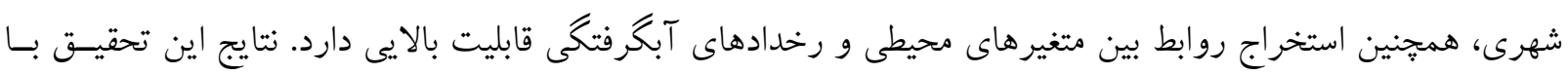

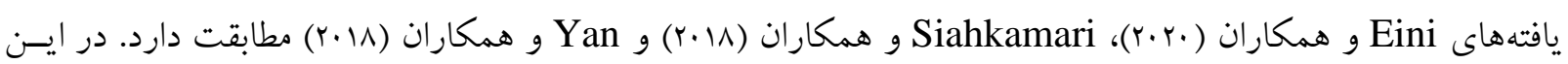

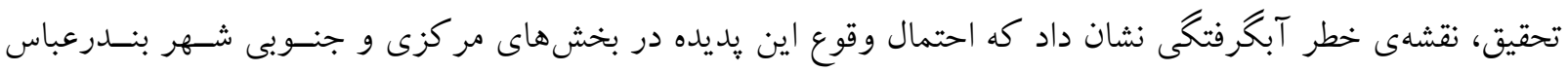

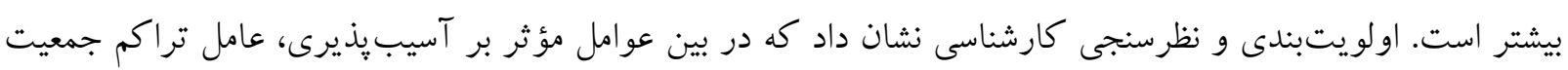

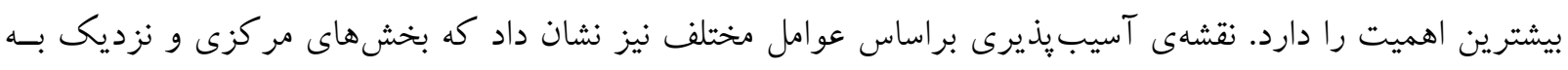

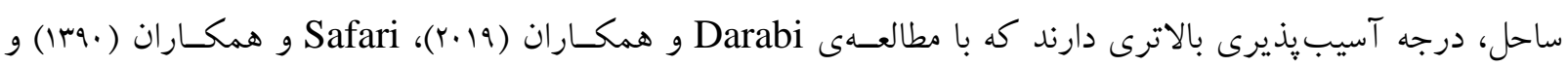
Majidi Heravi

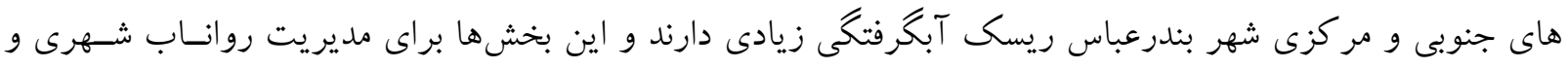

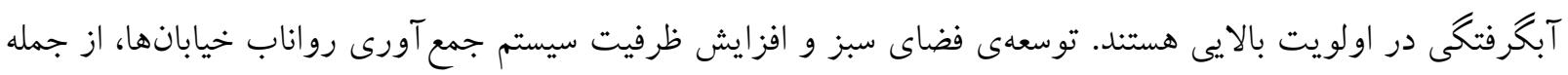

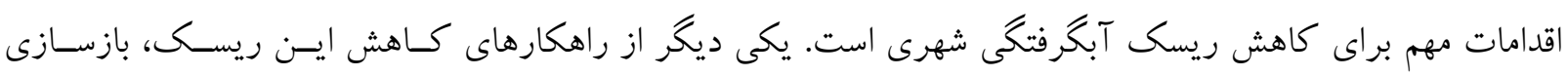
ساختمانهايى است كه مقاومت كمى دارند و در مواقع رخداد سيلاب شهرى ممكن است تخريب شوند يا آسيب جدى دهى دهري

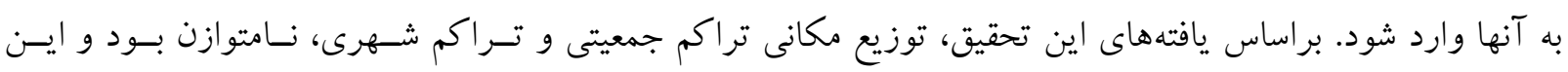

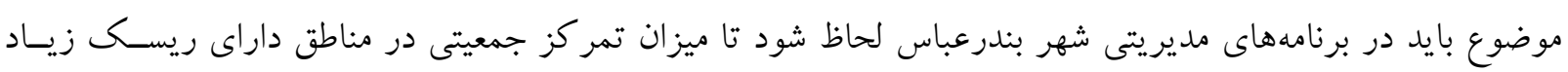
كاهش يابد.

\section{منابع}

1. 2Yan, J.; Jin, J.; Chen, F.; Yu, G.; Yin, H.; \& W. Wang, 2018. Urban flash flood forecast using support vector machine and numerical simulation, Journal of Hydroinformatics, 20(1), 221-231.

2. Akbarpoor, A.; Khasheie Siuki, A.; Keshavarz, A.; \& H. Furughifar, 2016. Determination of the Appropriate Sites to Rain Water Harvesting using Analysis Hierarchical Process (AHP), Watershed management, 6 (12), 65-74. (In Persian).

3. An ensemble prediction of flood susceptibility using multivariate discriminant analysis, classification and regression trees, and support vector machines, Science of the Total Environment, 651, 2087-2096.

4. Choubin, B.; Moradi, E.; Golshan, M.; Adamowski, J.; Sajedi-Hosseini, F.; \& A. Mosavi, 2019.

5. Convertino, M.; Troccoli, A.; \& F. Catani, 2013. Detecting fingerprints of landslide drivers: a MaxEnt model, Journal of Geophysical Research: Earth Surface, 118(3), 1367-1386. 
6. Costache, R.; Popa, M. C.; Bui, D. T.; Diaconu, D. C.; Ciubotaru, N.; Minea, G.; \& Q. B. Pham, 2020. Spatial predicting of flood potential areas using novel hybridizations of fuzzy decision-making, bivariate statistics, and machine learning, Journal of Hydrology, 124808.

7. Darabi, H.; Choubin, B.; Rahmati, O.; Haghighi, A. T.; Pradhan, B.; \& B. Kløve, 2019. Urban flood risk mapping using the GARP and QUEST models: A comparative study of machine learning techniques, Journal of hydrology, 569, 142154.

8. Dewan, A., 2013. Floods in a megacity: geospatial techniques in assessing hazards, risk and vulnerability, Dordrecht: Springer, 119-156.

9. Eini, M.; Kaboli, H. S.; Rashidian, M.; \& H. Hedayat, 2020. Hazard and vulnerability in urban flood risk mapping: Machine learning techniques and considering the role of urban districts, International Journal of Disaster Risk Reduction, 101687.

10. Ghahroodi Tali, M.; Majidi Heravi, A.; \& A. Abdili, 2016. Vulnerability due to urban floods (Case study: Tehran, Darkeh to Kan), Geography and environmental hazards, 17, 21-35. (In Persian).

11. Heravi, M, 2014. Vulnerability due to urban floods in the northwest of Tehran Journal of Geography. 46: 181-202.

12. Hosseinzadeh, S.R, 2004. Environmental Crises in Iranian Metropolitan Cities Sustainable City Book , p:183. Witpress England.

13. Hwang, C., \& K. Yoon., (1980). Multiple attribute decision making, in lecture notes in economics and mathematical systems, 186: Springer-Verlag, Berlin.

14. Isazadeh, M.; Biazar, S. M.; \& A. Ashrafzadeh, 2017. Support vector machines and feed -forward neural networks for Spatial modeling of groundwater qualitative parameters, Environmental Earth Sciences, 76(17), 610-625.

15. Jaafari, A.; Najafi, A.; Pourghasemi, H. R.; Rezaeian, J.; \& A. Sattarian, 2014. GISbased frequency ratio and index of entropy models for landslide susceptibility assessment in the Caspian forest, northern Iran, International Journal of Environmental Science and Technology, 11(4), 909-926.

16. Kavzoglu, T., \& I. Colkesen., (2009). A kernel functions analysis for support vector machines for land cover classification. International Journal of Applied Earth Observation and Geoinformation. 11, 352-359.

17. Paquette, J., \& J. Lowry, (2012). Flood hazard modelling and risk assessment in the Nadi River Basin, Fiji, using GIS and MCDA. The South Pacific Journal of Natural and Applied Sciences. 30(1), 33-43.

18. Paul, G. C.; Saha, S.; \& T. K. Hembram, 2019. Application of the GIS-based probabilistic models for mapping the flood susceptibility in Bansloi Sub-basin of Ganga-Bhagirathi River and their comparison, Remote Sensing in Earth Systems Sciences, 2(2-3), 120-146.

19. Phillips, S. J.; Anderson, R. P.; \& R. E. Schapire, 2006. Maximum entropy modeling of species geographic distributions, Ecological modelling, 190(3-4), 231259.

20. Pourghasemi, H. R.; Moradi, H. R.; \& M. Mohammadi, 2014. Landslide Susceptibility Zoning, Using Weight of Evidence Probabilistic, Geospetial information Technology, 1 (2), 69-80. (In Persian).

21. Rezaei, S.; Nadery, S.; \& P. Karami, 2017. Spring and summer habitat suitability modeling of wild boar (Sus scrofa) in Jassb wildlife refuge of Arak using Maximum Entropy (MaxEnt) method, Journal of Animal Environment, 9(2), 25-36. 
22. Rustayi, S.H. and Jananeh, K, 2018. Zoning the risk of slope instability in the potential catchment area of Ardabil Chay using fuzzy hierarchical method, Journal of Geography and Planning. 23(70): 169-188.

23. Safari, A.; Pourfarzaneh, S.; \& A. J. Musivand, 2011. Assessing the vulnerability of urban areas to flood risk using GIS and fuzzy logic Case study: Tehran Region 3, Applied Research in Geographical Sciences, 17(20), 129-150. (In Persian).

24. Sahana, M.; Rehman, S.; Sajjad, H.; \& H. Hong, 2020. Exploring effectiveness of frequency ratio and support vector machine models in storm surge flood susceptibility assessment: A study of Sundarban Biosphere Reserve, India, Catena, 189, 104450.

25. Saremi, N.; Bazrafshan, O.; Esmaelpour, Y.; \& M. Sour, 2018. Flood Zoning and Assessment of Surface Runoff Channels Efficientcy in Bandar-Abbas Urban Watershed, Journal of Iran-Watershed Management Science \& Engineering, 42(12), 42-51. (in Persian)

26. Seyedian, M, 2013. River flow forecasting using data mining and time series, Journal of Echo Hydrology. 1(3): 167-179.

27. Shin, S.; Kyung, S.; Lee, T.; \& Kim, J.H, 2005. An application of support vector machines in bankruptcy perdiction model, expert system with application, 28:127135.

28. Siahkamari, S.; Haghizadeh, A.; Zeinivand, H.; Tahmasebipour, N.; \& O. Rahmati, 2018. Spatial prediction of flood-susceptible areas using frequency ratio and maximum entropy models, Geocarto international, 33(9), 927-941.

29. Tabarestani, S.H, 2020. Evaluation of flood potential in the watershed of Mazandaran province by AHP method, Journal of Environment and Water Engineering. 6(4): 331-341. (in Persian)

30. Vafakhah, M.; Loor, S. M. H.; Pourghasemi, H.; \& A. Katebikord, 2020. Comparing performance of random forest and adaptive neuro-fuzzy inference system data mining models for flood susceptibility mapping, Arabian Journal of Geosciences, 13, 417. 


\title{
Risk analysis of urban flood in Bandar Abbas using Machine Learning model and Analytic Hierarchy Process
}

\author{
Yousef Ahmadi: Ph.D Student in Watershed Management, Natural Resources Department, Faculty of \\ Agriculture \& Natural Resources, University of Hormozgan, BandarAbbas \\ Ommolbanini Bazrafshan": Associate professor, Natural Resources Department, Faculty of Agriculture \& \\ Natural Resources, University of Hormozgan, BandarAbbas, Iran \\ Ali Salajeghe: Professor, Department of Arid and Mountainous Regions Reclamation, Agriculture \& Natural \\ Resources Campous, University of Tehran, Karaj, Iran. \\ Arashk Holisaz: Assistant Professor, Watershed Management Department, Gorgan University of Agricultural \\ Sciences and Natural Resource, Gorgan, Iran \\ Ali Azare: Assistant Professor, Department of Geography, Faculty of Human Science, Jiroft University
}

Article History (Received: 2021/03/12

Accepted: 2021/04/17)

\section{Extended abstract}

\section{1- Introduction}

Floods are one of the natural events that cause human casualties and damage to buildings, facilities, gardens, fields, and natural resources every year. Urbanization disturbs the balance of slopes through indirect intrusion within watersheds, kills vegetation, soil compaction, and changes in the profile of waterways, increases the severity of floods, and increases the amount of sediment generated. At the foot of the mountain, which includes the city's physical fabric expansion area, the natural drainage pattern disrupts and increases the risk of urban flooding. On the one hand, because of its geographical position and the heavy rainfall regime over a short period of time, and on the other hand, because of its significant growth and development, especially during the last decade, and because of its location, the town of Bandar Abbas faces flood problems. On the other hand, flood risk zoning has not been considered so far in order to be used in the planning and management of flood protection and control in Bandar Abbas, and not much work has been done in this area in the form of research and even studies. Flood risk zoning is therefore important in order to forecast the degree of flood damage under various circumstances and the economic and social basis for flood control and containment systems. Risk modeling and flood vulnerability mapping will play an important role in future decision-making, flood management, and land management in the area of the study in some cases.

\section{2- Methodology}

In general, the first step in the implementation of research in watershed management, environmental, natural resources, agriculture, etc. projects is the preparation of the data used in that project. The data needed to investigate the hazard, vulnerability, and risk of urban floods in Bandar Abbas in the first stage are: 1- Height 2- Land slope 3- Distance from water table 4- Water transport capacity of canal 5- Distance from river 6- Distance from collection network of surface runoff was obtained from Iran Water Resources Management Organization and city demographic data Bandar Abbas was prepared by the Statistics Center of Iran. A map of four key factors, including building quality, urban density, population density and, socioeconomic status, has been prepared to examine the vulnerability. Two models of Maximum Entropy (MaxEnt) and Support Vector Machine (SVM) were used to investigate the risk, vulnerability, and risk of flooding and urban flooding in Bandar Abbas. Then, the Area under Curve (AUC) obtained from the curve ROC was used in order to test the model's efficiency. After estimating flood hazard, a hierarchical analysis model was used in order to estimate flood vulnerability in this report. Finally, the map of flood risk was obtained based on hazard and vulnerability maps.

\section{3- Results}

Based on the Maximum Irregularity Model, the results obtained from the flood risk prediction map showed that the southern parts of Bandar Abbas had a greater likelihood of flooding. It is also likely that parts of 
Bandar Abbas city center will be flooded. Bandar Abbas western and eastern areas are less likely to be flooded. Support has also shown that the southern, eastern, and southwestern regions are listed as likely to undergo urban flooding in order to help control urban floods. Using the SVM, the flood prediction map shows that the southern, eastern, and southwestern areas are more likely to flood; however, the northern and northwestern parts of Bandar Abbas are less likely to flood. The AUC was used in order to prepare the models. In the two phases of training and validation, the accuracy of the model suggests the highest irregularity. The Maximum Entropy Model, based on these curves, was $99.7 \%$ accuracy in the training phase and $94.2 \%$ accuracy in the validation phase. Therefore, in both the training and validation phases, the MaxEnt had excellent performance (area under the curve about 90\%). The findings of hierarchical analysis have shown that the most important effective criterion for vulnerability is population density. The standard of construction, urban density and socio-economic status were ranked second, and fourth, respectively. Finally, on the basis of the risk map review, it can be claimed that there is a higher degree of risk in the southern parts of Bandar Abbas and parts of Bandar Abbas city center.

\section{4- Discussion \& Conclusions}

The results of the model accuracy evaluation show that SVM has accuracy in flood probability spatial prediction and in identifying areas vulnerable to flooding. It can also be seen that the SVM had better performance than the model of the support vector machine. Since most urban areas such as Bandar Abbas lack reliable hydraulic and hydrological knowledge, a new approach to flood management and urban flooding may be the use of machine learning models and historical urban flooding events. Machine learning models are highly capable of spatial analysis of flood events and urban flooding, as well as extracting the relationships between environmental variables and flood events, based on the tests conducted. The flood risk map revealed in this analysis that the central and southern sections of Bandar Abbas are more susceptible to flood. Prioritization and expert studies have shown that among the factors influencing vulnerability, the population density factor is the most significant. The map of vulnerability based on different factors also showed that there is a greater degree of vulnerability in the central and coastal areas. Comprehensive flood risk analysis has shown that there is a high risk of flooding in the southern and central parts of Bandar Abbas and these areas have a high priority for urban runoff and flood control.

Key Words: Flood Vulnerability; Spatial Prediction; Support vector machines; Maxent model 